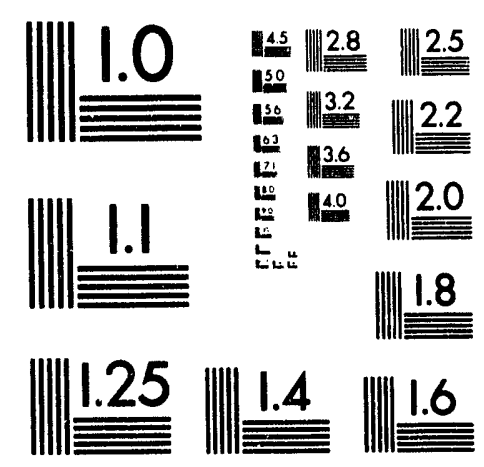



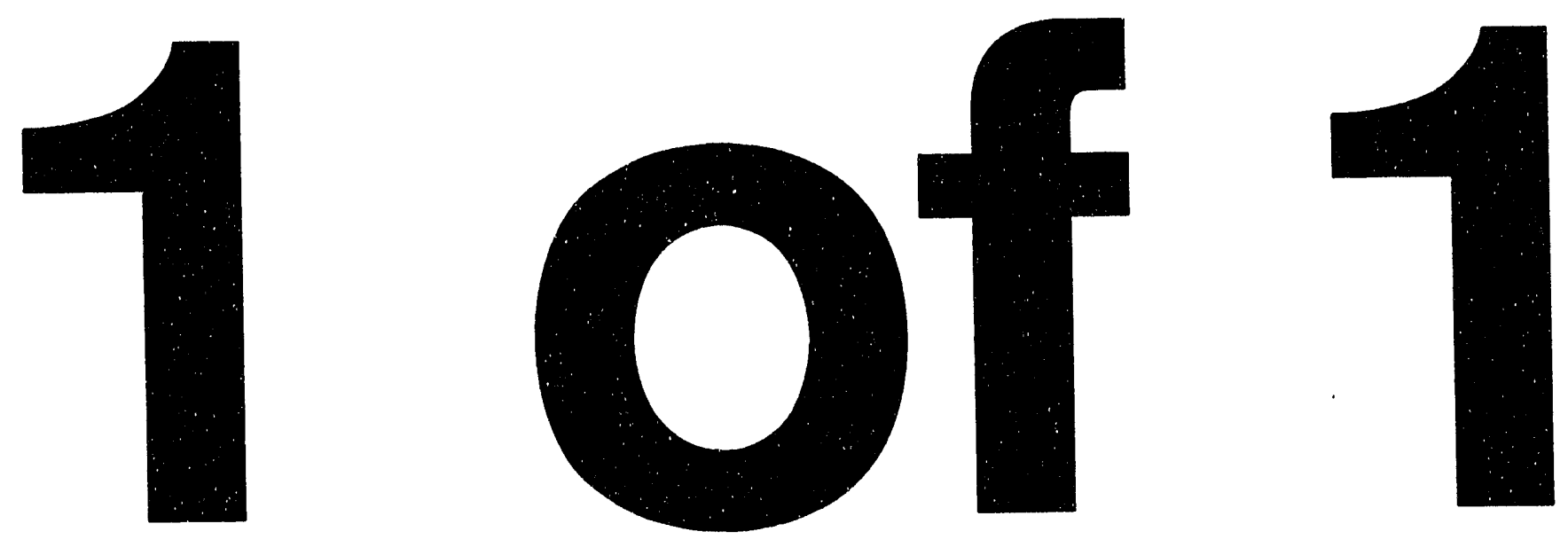


\title{
A Methodology for the Evaluation of the Turbine Jet Engine Fragment Threat to Generic Air Transportable Containers
}

\author{
D. C. Harding and J. D. Pierce \\ Department 6642 \\ Sandia National Laboratories ** \\ Albuquerque, NM 87185
}

\begin{abstract}
Uncontained, high-energy gas turbine engine fragments are a potential threat to air-transportable containers carried aboard jet aircraft. The threat to a generic example container is evaluated by probability analyses and penetration testing to demonstrate the methodology to be used in the evaluation of a specific container/aircraft/engine combination. Fragment/container impact probability is the product of the uncontained fragment release rate and the geometric probability that a container is in the path of this fragment. The probability of a high-energy rotor burst fragment from four generic aircraft engines striking one of the containment vessels aboard a transport aircraft is approximately $1.2 \times 10^{-9}$ strikes/hour. Finite element penetration analyses and tests can be performed to identify specific fragments which have the potential to penetrate a generic or specific containment vessel. The relatively low probability of engine fragment/container impacts is primarily due to the low release rate of uncontained, hazardous jet engine fragments.
\end{abstract}

* This work was performed at Sandia National Laboratories, Albuquerque, New Mexico, and supported by the U. S. Department of Energy under Contract DE-AC04-76P00789.

** A U.S. Department of Energy Facility 


\section{Acknowledgments}

Special thanks to Glenn Hohnstreiter (6642) and R. E. Luna (6603) for their guidance throughout this investigation. J. L. Moya (1513) provided literature review. Mona Aragon, Maxine Norton, Mary Monson, and Hilda Mosley in our Information and Communication Services Center (7100) provided valuable support as well. Thanks also to D. J. Ammerman (6642) and J. D. McClure (6641) for their draft document review. 


\section{Table of Contents}

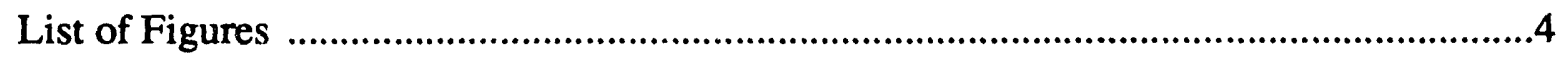

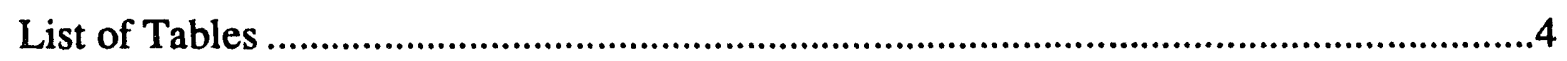

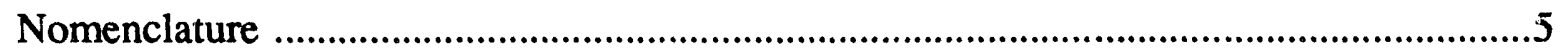

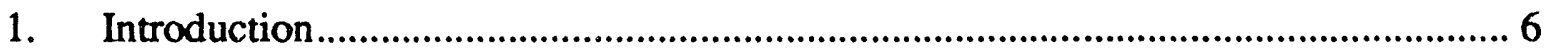

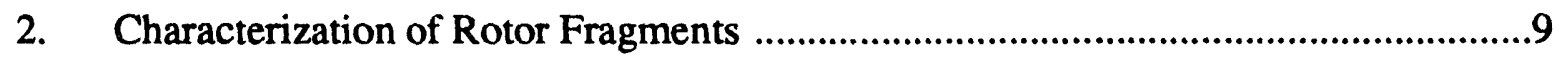

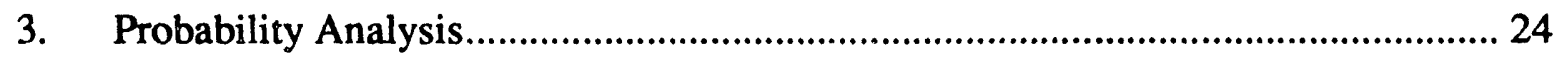

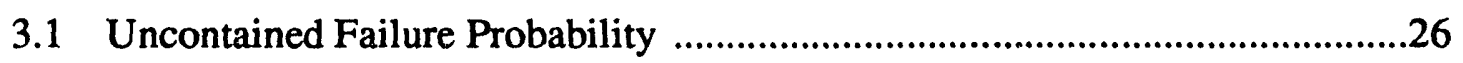

3.2 Geometric Probability ............................................................................... 30

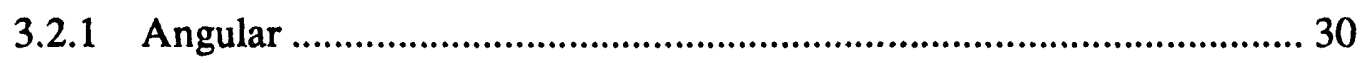

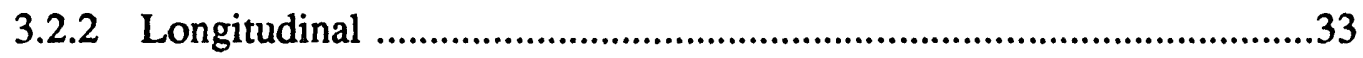

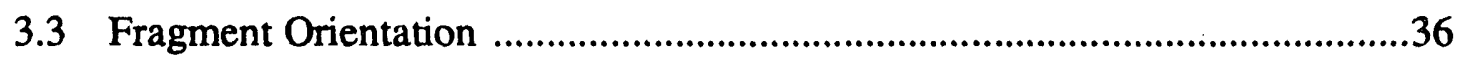

3.4 Fragment Penetrating Ability ......................................................................... 37

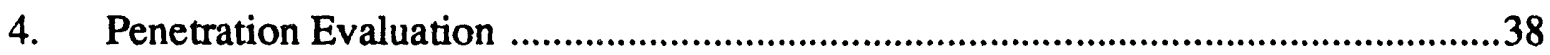

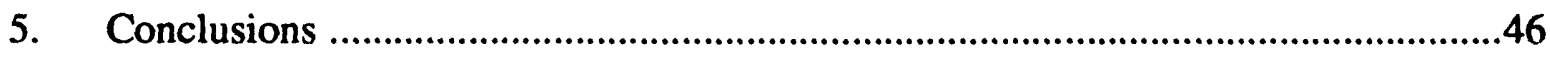

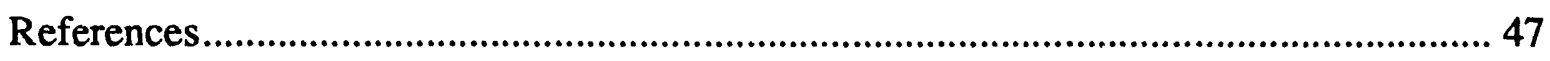




\section{List of Figures}

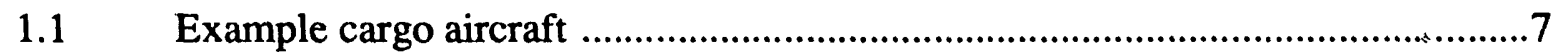

$1.2 \quad$ Aircraft loading limits and possible cargo container locations ..............................

2.1 Fatigue crack origins and paths in rotors ......................................................11

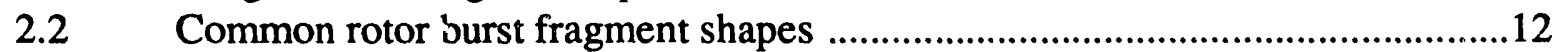

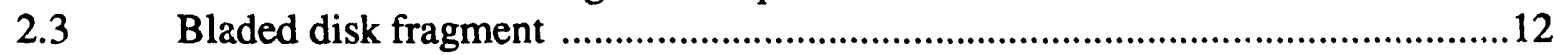

$2.4 \quad$ Typical separated disk segments ....................................................................13

2.5 Stage 1 fan disk (reconstructed with blades ........................................................14

2.6 GE CF6-80C2 engine ................................................................................16

2.7 Gas turbine engine chambers (from similar CF6-6 engine) ...............................17

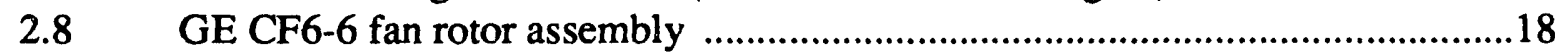

$2.9 \quad$ CF6-6 fan disk cutaway view .......................................................................

$2.10 \quad$ Rotational vs. translational disk energies ..........................................................20

2.11 Typical intercontinental cargo aircraft flight profile $\left(\mathrm{N}_{1}\right.$ vs. $\left.\mathrm{t}\right)$..........................22

2.12 Typical intercontinental cargo aircraft flight profile ........................................23

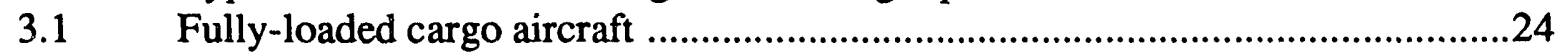

3.2 Generic air-transport container with tie-downs inside a cargo container ...........25

3.3 Fan disk impact probability event tree ................................................................26

3.4 Uncontained gas turbine engine failures, 1962-1986 .......................................27

3.5 Angular and longitudinal engine fragment paths ............................................31

3.6 Fan blade and disk angular impact regions ............................................................33

3.7 Longitudinal fragment impact regions (all frags.) ……...........................................35

3.8 Longitudinal fan component impact regions .......................................................35

4.1 GE CF6-80C2 engine cross-section with fan module ..........................................41

$4.2 \quad 134^{\circ}$ fan disk segment solid model (bottom view) ............................................42

$4.3 \quad 134^{\circ}$ fan disk segment solid model (isometric view) ..........................................43

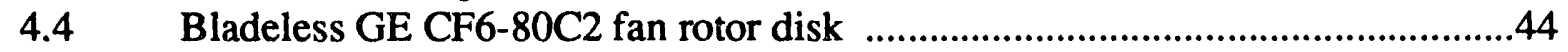

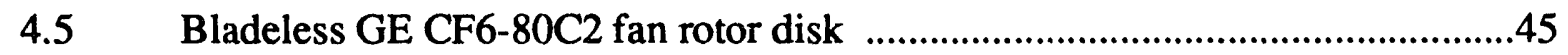

\section{List of Tables}

2.1 Penetrating abilities of various engine fragments, or KE/A ..............................21

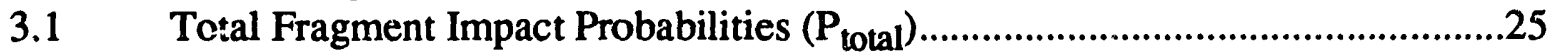

3.2 U.S. Uncontained Engine Rotor Failure Incidents: 1976-1986 ........................27

3.3 U.S. Uncontained Rotor Failures Fy Fragment Type in $1986 \ldots \ldots \ldots \ldots \ldots \ldots \ldots \ldots \ldots \ldots . . .28$

3.4 Average of 1976-1986 Uncontained Fragment Generation Rates.......................29

3.5 Sample Uncontained Fragment Probabilities...................................................29

3.6 Angular Fragment-to-Primary Containment Vessel Impact Probabilities...........32

3.7 Longitudinal Fragment-to-Primary Containment Vessel Impact Probabilities ..36 


\section{Nomenclature}

\section{English}

c.g. Center of Gravity

$\mathrm{D}_{\mathrm{E} 1} \quad$ Distance from Containment Vessel to Inner Engine

$D_{\mathrm{E} 2}$ Distance from Containment Vessel to Outer Engine

F.W. Fragment Width

g Acceleration of Gravity

HPC High Pressure Compressor

HPT High Pressure Turbine

I Mass Moment of Inertia

$\mathrm{L}_{\mathrm{C}} \quad$ Length of Primary Containment Vessel

LIGO Local Isotropic Global Orthotropic

m Mass

$\mathrm{N} \quad$ Number of Containers

$N_{1} \quad$ Aircraft Engine Power Level

P Probability

rpm Revolutions Per Minute

V Velocity

\section{Greek}

$\rho \quad$ Density

$\omega$ Rotational Rate, $\mathrm{rad} / \mathrm{sec}$ 


\section{Introduction}

Transportation of hazardous materials via cargo aircraft has been questioned due to the potential impact of on-board containers by high-energy engine fragments in the rare case of rotor failure. A large transport aircraft, the Boeing 747-400 (see Figure 1.1), is used as an example cargo aircraft to characterize potential rotor fragments and the probabilities of fragment/container impacts for the performance of an overall probabilistic risk assessment (PRA) of the transport mode. This fully-loaded aircraft can hold 29 standard 8-ft. x 8-ft. x 10-ft. cargo containers on its main cargo deck, each with one generic container inside, as illustrated in Figure 1.2. A fully-loaded aircraft is desirable from an efficiency standpoint to minimize the number of dedicated aircraft flights. Four General Electric CF6-80C2 engines are used as an example of typical cargo aircraft engines and are only used to provide representative shapes and masses for this study. This study is to evaluate the problems in general and is in no way intended to be a performance evaluation of the Boeing 747-400 aircraft or the GE CF6-80C2 engines.

Intensive studies and programs have been performed by governmental agencies, universities, and private industry to evaluate and reduce the threat to critical aircraft components from uncontained engine rotor burst fragments [1-26]. These have involved analyzing and strengthening engine casing containment rings, compiling statistics on gas turbine engine failures, characterizing fragments, assessing fragment strike probabilities, and evaluating ways to either contain or deflect failed engine components.

Structural impact damage by non-contained engine burst debris has become important to not only aircraft designers, but also commercial transport agencies and the public in view of recent serious incidents to large transport aircraft. The most recent demonstration in the United States of the damage potential presented by engine burst debris is the crash of United Airlines (UAL) Flight 232 in Sioux City, Iowa, on July 19, 1989, that was caused by a catastrophic failure of the tailmounted engine, leading to loss of the airplane's flight control hydraulic systems [27].

A probability analysis was used to determine the chance of fragment/container impact and a combination of penetration testing and analyses should be used to assess the ensuing container damage. A generic plutonium air transport package was used for puncture/penetration evaluation since the current plutonium air transport regulations (NUREG-0360 [38]) are the most comprehensive for air transport packagings. The probability analysis includes characterizing engine burst fragments, determining the likelihood of uncontained engine bursts producing specific fragments, and assessing the geometric probability of a fragment impact. The package's resistance to accidents can be evaluated through a series of analyses and tests even though overall risk is made very small by expected accident frequency. 

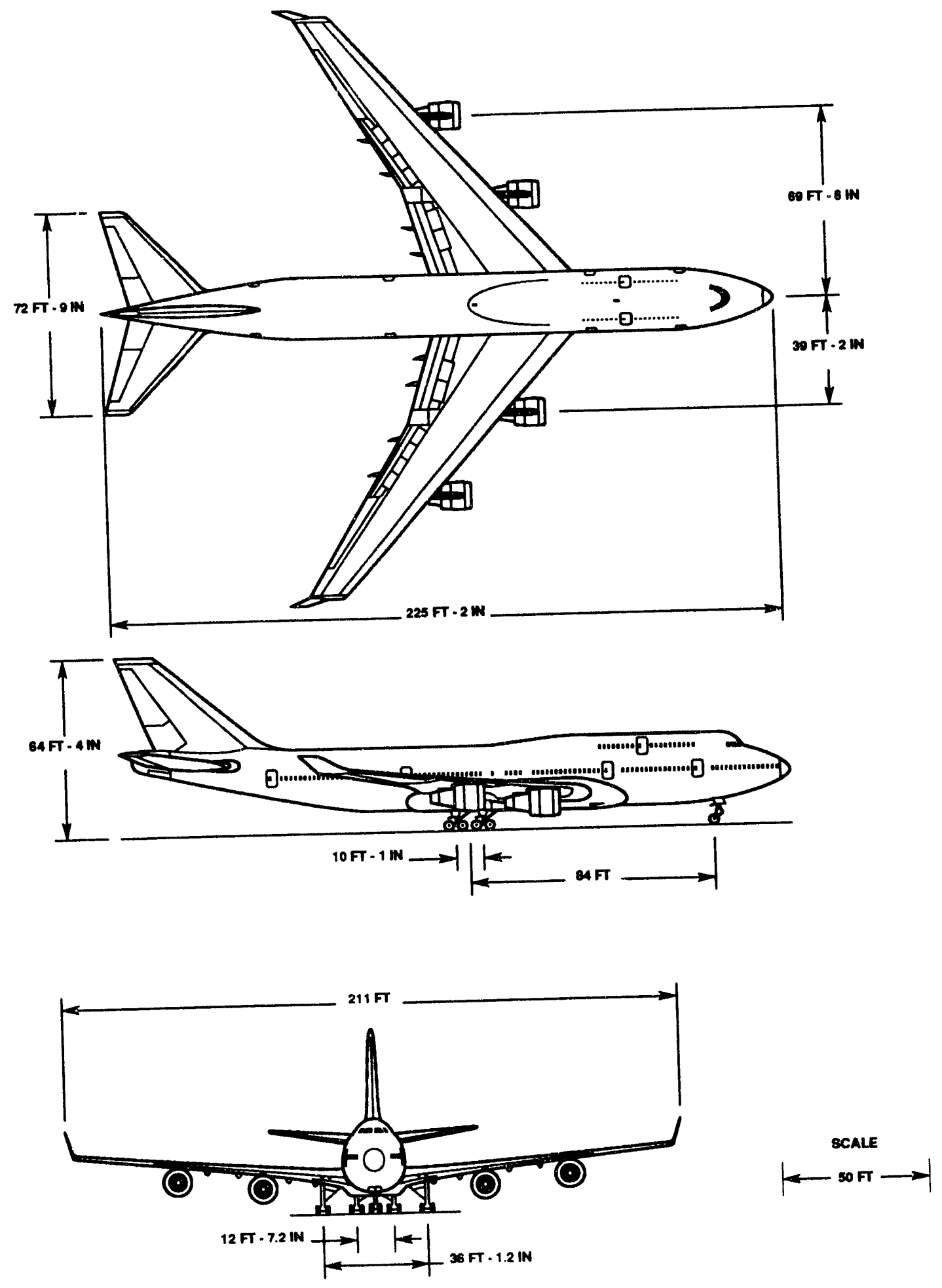

Figure 1.1 Example cargo aircraft 

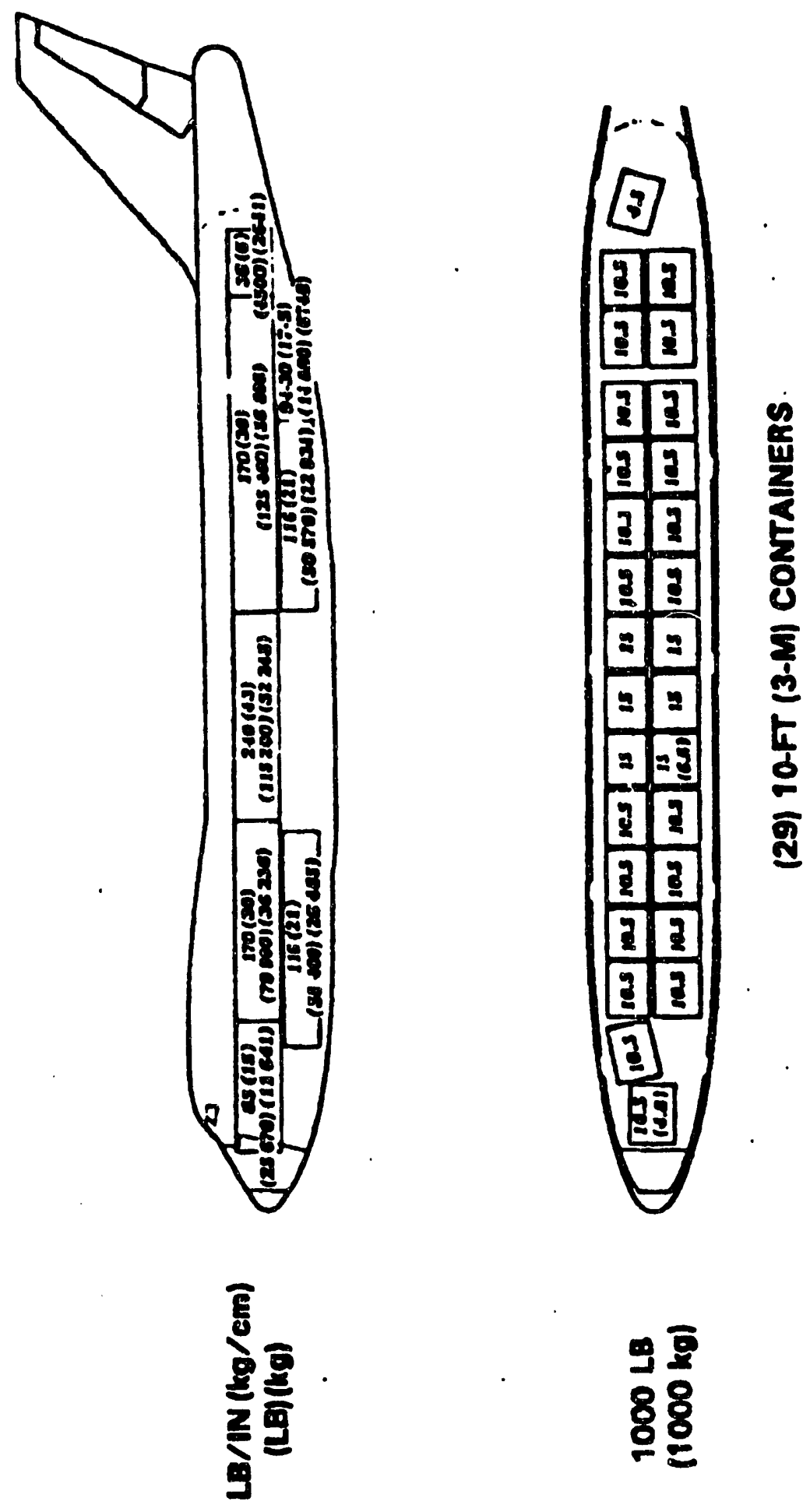

Figure 1.2 Aircraft loading limits and possible cargo container locations 


\section{Characterization of Rotor Fragments}

Jet engine rotor bursts, although rare, are caused by a number of mechanical and operational factors. Fatigue is a major problem that limits a rotor disk's service life. It is a mechanical phenomenon that causes a disk to fracture by repeated or fluctuating stresses that have maximum values, each of which is less than the ultimate tensile strength of the disk. Disks are subjected to either high- or low-with-high-cycle fatigue. High-cycle fatigue results from a large number of loading cycles at relatively low stress levels. Low-cycle fatigue results from a low number of loading cycles at relatively high stress levels. Figure 2.1 shows typical fatigue crack origins and paths for both high- (A through $E$ ) and low-with-high-cycle (F through $M)$ fatigue [23].

In addition to high- and low-cycle fatigue, fan, compressor, and turbine disks have failed as a result of engine assembly errors, substandard material, bearing failure, overheating, engine overspeed, operating interference from stator, blade, or component failures, and foreign object damage. Rotor disk failures, by far the most dangerous to the aircraft and its cargo, have also been caused by a combination of these factors $[3,5,6,22,23,25]$.

The United States Federal Aviation Administration (FAA) regulations state that all gas turbine aircraft engines used in the United States must have engine casings that will contain individual blade failures from fans, compressors, and turbines [28]. This must be proven by the aircraft engine manufacturer by either testing or analysis. Even with this regulation, individual blade failures do occur that are uncontained [7-11]. They are sometimes associated with rotor disk bursts consisting of a wide array of high-energy fragments that may provide a pathway for the blades through the casing. More often, though, multiple blade failures will result in a breach of the engine casing. The energy of a contained blade is used up in stretching and bulging the casing. This causes localized weakening in the casing and if a second blade impacts the same bulge the casing is likely to fail [2].

Characterization of the wide array of uncontained rotor fragments can yield valuable information in the assessment of penetration hazards to on-board generic containers. For several years there has been a combined program to establish statistics, perform experiments, and develop analytical methods at NASA Lewis Research Center, the Naval Air Propulsion Test Center, and Massachusetts Institute of Technology. Many tests haye been performed in spin chambers $[1,2,5,29]$ to both characterize fragments and benchmark analytical determinations of engine casing strengths. Some of this work led to the inclusion of lightweight aramid fiber fabric in a sandwich configuration within the casing of many mudern engines to contain blades and other smaller fragments.

The shapes of the most common fragments are shown in Figure 2.2 [2,5]. Individual blades, rim sections, bladed rim sections, disk sections, and bladed disk sections comprise the majority of uncontained jet engine fragments. Diagram $\mathrm{N}$ shows a disk failure through the bore, whereas diagram $P$ shows a complete rim release in sections. Diagrams $O$ and $Q$ show smaller fractions of the disk, sometimes accompanied by free blades. Diagram $\mathbf{R}$ details two common blade release modes: by fracture of "fir-tree" roots or shearing of "fir-tree" teeth. Figure 2.3 shows a typical 1/3 
bladed disk fragment as it looks immediately after the burst event and how it could look after penetrating the engine casing. Some researchers have argued that blades are much more likely to fracture at the blade root as opposed to simply bending over as the figure suggests [2]. Blade fracture, yielding an unbladed disk fragment after engine casing penetration, is especially likely with brittle blade materials like titanium alloy.

Both brittle fracture and ductile bending of bladed disk sections have occurred in spin chamber tests and in flight. Figures 2.4 and 2.5 show typical separated disk segments recovered from actual uncontained in-flight incidents. The latter figure is a stage 1 fan disk that burst at cruise altitude severing primary and secondary hydraulic lines causing United Airlines Flight 232 to crash land in Sioux City, Iowa, on July 19, 1989 [27]. The fragments were retrieved from a corn field below the airspace where the fan disk burst. This is the most recent example of the damage such high-energy fragments can cause.

Probabilities of various rotor burst fragment sizes, weights, and shapes have not been comprehensively compiled in the literature. This should be expected since these events are extremely rare, as is the recovery of all fragments from an event for characterization. Obviously, engine type and size would have a significant effect on fragment characterization. The newer generation highbypass ratio engines with a large (94-inch) diameter fan could generate large fragments: up to 31 inches for fan blades and up to 30 inches for $134^{\circ}$ fan disk sections. The kinetic energy of a $134^{\circ}$ disk section is 33.1 million inch-pounds with attached blades and 14.7 million inch-pounds without blades, before penetration of the engine casing.

The generally-accepted "worst-case" engine fragment released from rotor bursts is the $1 / 3$ "pie"-shaped bladed disk section. Debris mass is generally broken down into $1 / 20$ bladed disk and $1 / 3$ bladed disk section groups. During a given significant non-containment, $1 / 20$-disk sections will have a $66 \%$ chance of being released and $1 / 3$-disk sections will have a $33 \%$ chance $[2,25]$. Section 3.1 in this report details probabilities of various fragment types per hour of engine flight time. 

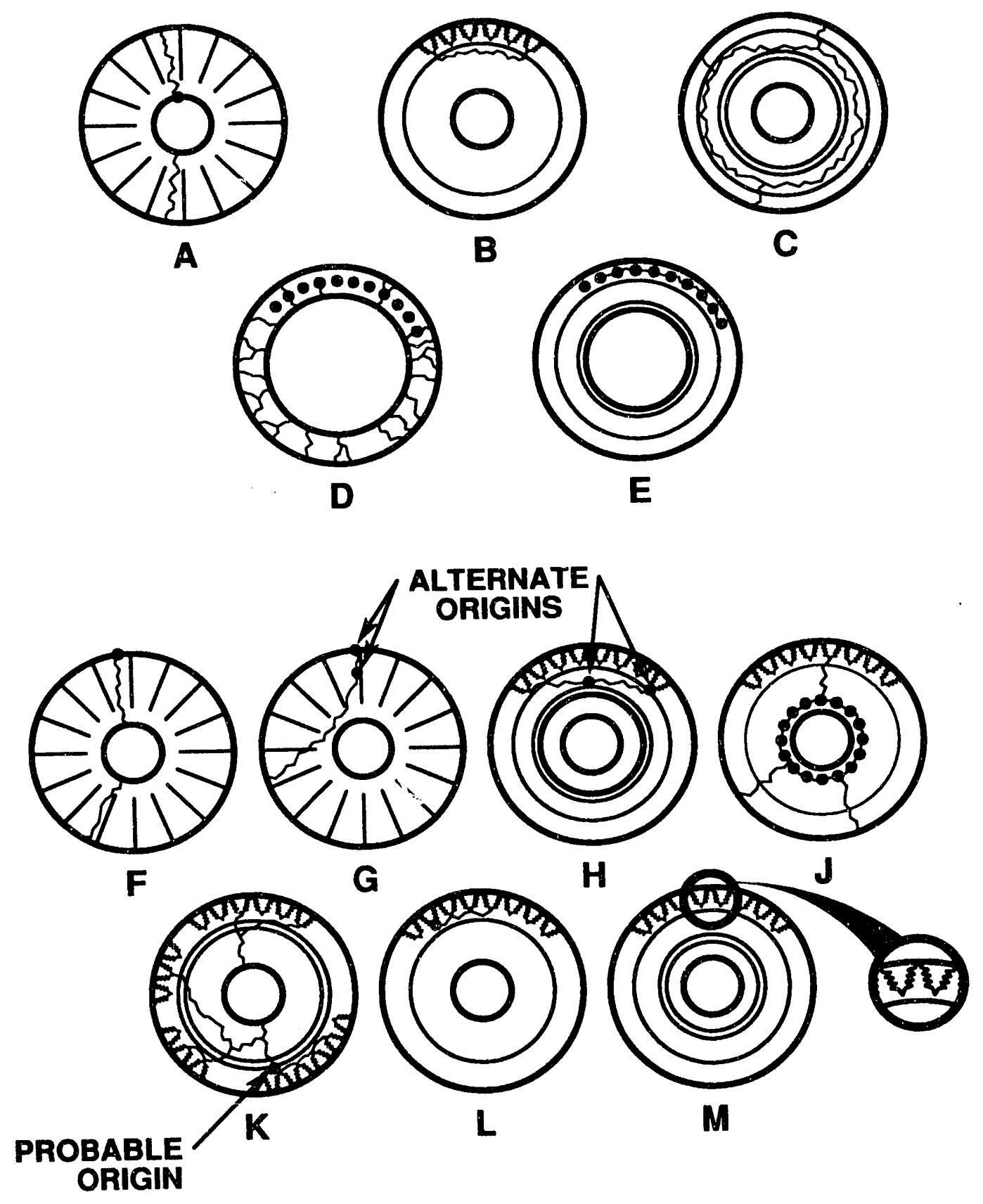

\section{- ORIGIN}

Figure 2.1 Fatigue crack origins and paths in rotors 


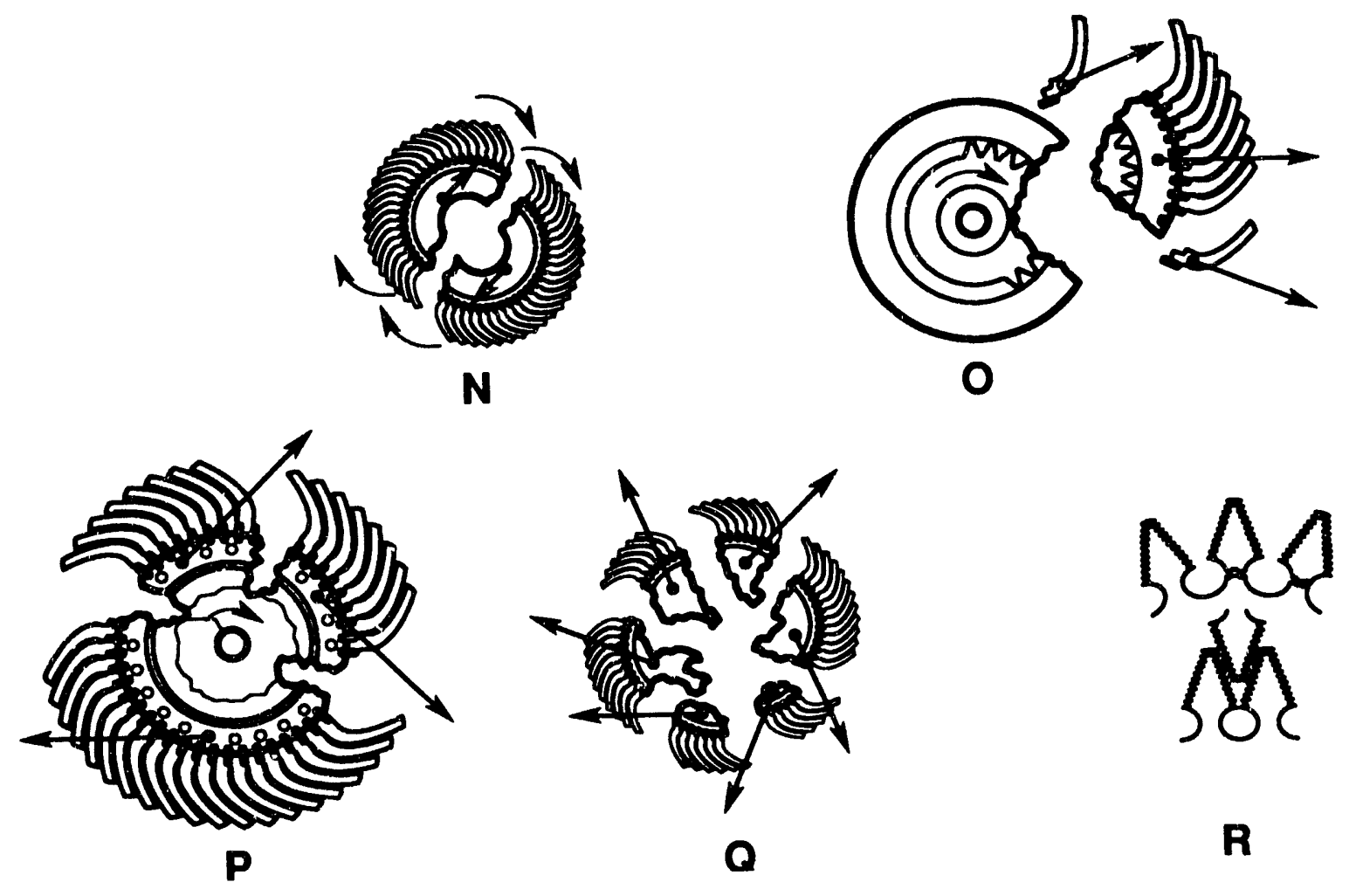

Figure 2.2 Common rotor burst fragment shapes

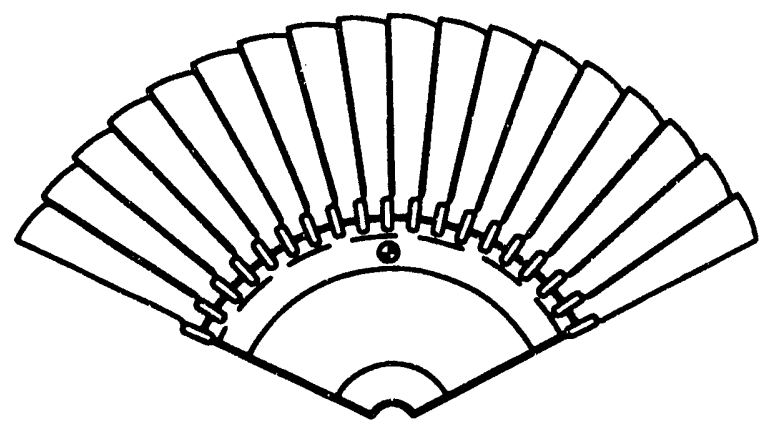

BEFORE IMPACT

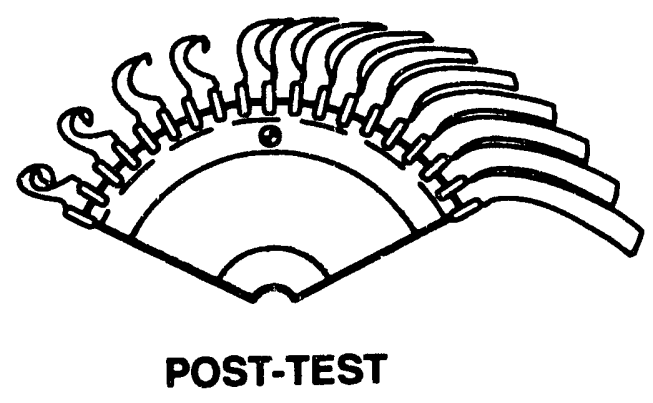

Figure 2.3 Bladed disk fragment 


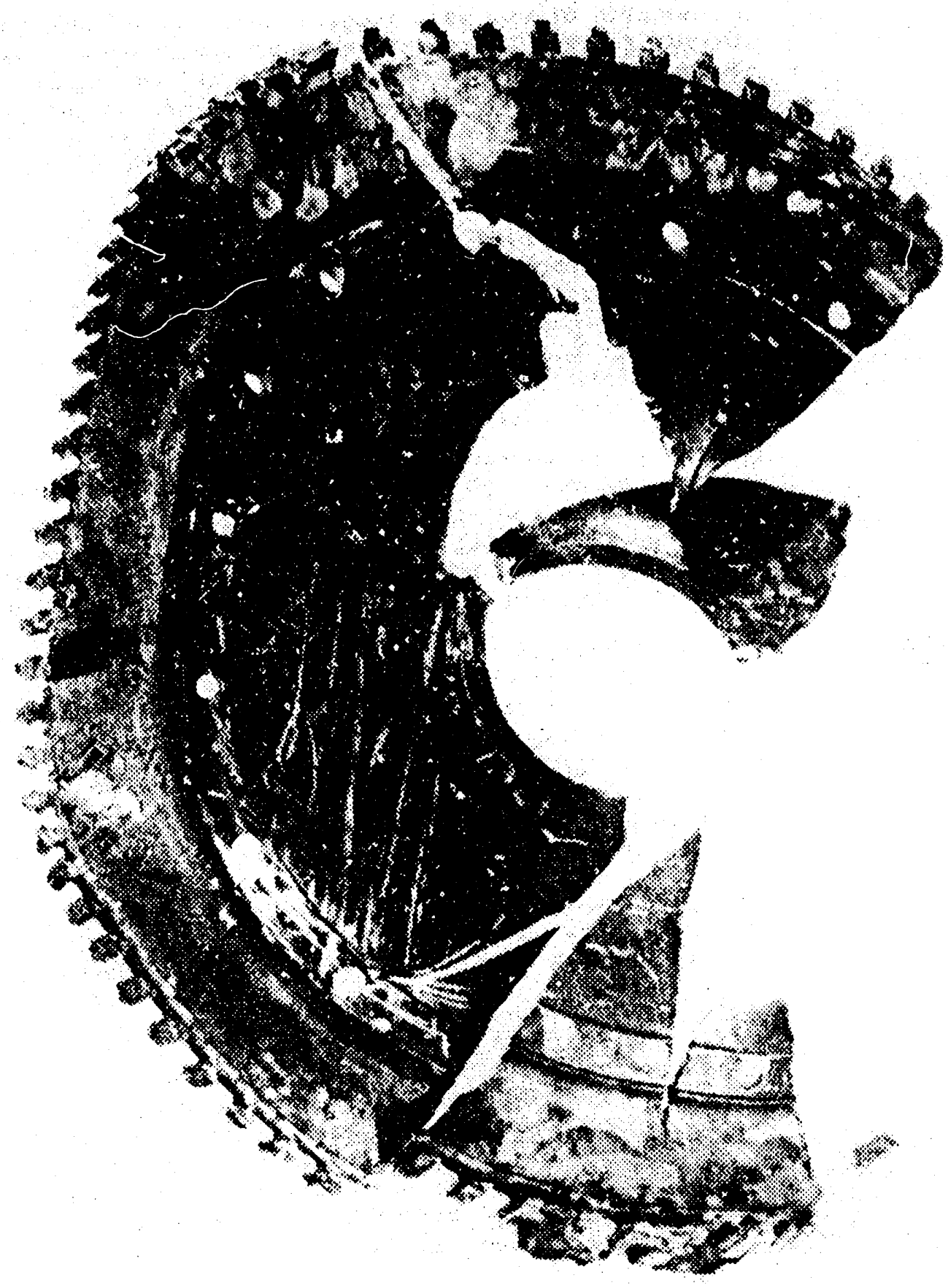

Figure 2.4 Typical separated disk segments (from [27]) 


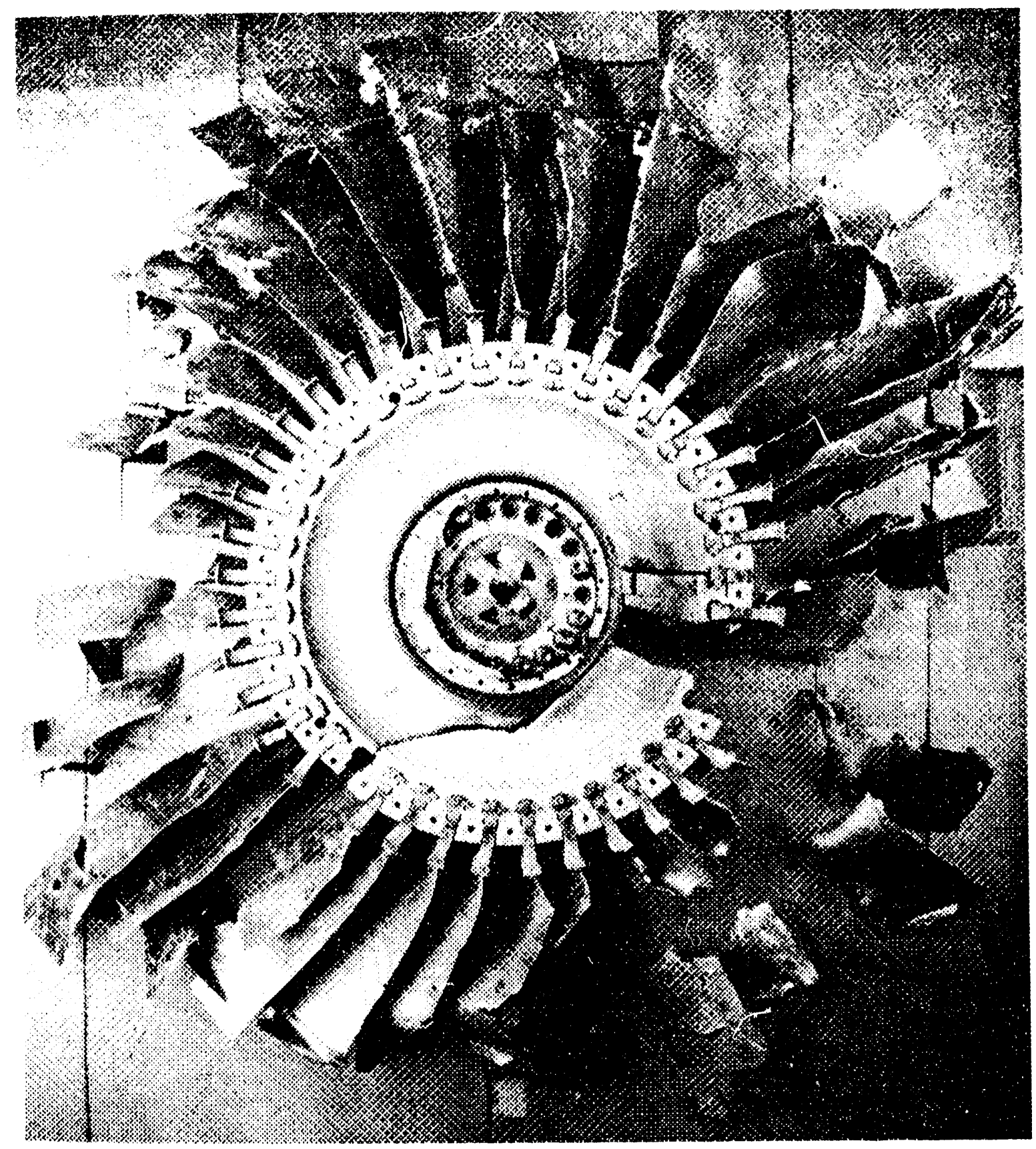

Figure 2.5 Stage 1 fan disk (reconstructed with blades, from |27|) 
The Boeing 747-400 cargo aircraft with four General Electric CF6-80C2 high-bypass engines is merely one example aircraft to demonstrate the methodology. Although there are no uncontained burst data available on this new engine, statistics from other slightly older engines, including the GE CF6-50 series, are assumed to be similar in shape, type, and distribution. Since uncontained failure rates over the past 16 years have held relatively constant [7], this assumption is valid. Undor:umented records of the newer CF6-80C2 engine suggest that this assumption is conservative. The newer -80 series engines do have an aluminum/Kevlar composite casing in contrast with the -50 series' steel casing, but the improvement is for weight savings and reduction of secondary damage.

A three-dimensional cutaway view of the CF6-80C2 is shown in Figure 2.6 [30]. It is a dual rotor, axial flow high bypass turbofan. The 14-stage compressor is driven by a 2-stage high pressure turbine and the integrated front fan and low pressure compressor is driven by a 5-stage low pressure turbine. The primary sections of the engine include the fan, low-pressure compressor, high-pressure compressor, combustion chamber, high-pressure turbine, and low-pressure turbine, as shown in Figure 2.6 [31] and 2.7. Each fan, compressor, and turbine section contains rotor disks with blades that may burst into high-energy fragments. Figures 2.8 and 2.9 [27] show more detail of the stage 1 fan from an older and slightly smaller GE CF6-6 engine (the one that failed in the UAL 232 crash), similar to the CF6-80C2.

The GE CF6-80C2 engine has two rotors that have two different maximum operating speeds: the low-pressure rotor that can spin at up to $3,854 \mathrm{rpm}$, and the high-pressure rotor that can spin at up to $11,055 \mathrm{rpm}$ at redline. Rotors include hubs, disks, rims, drums, seals, and spacers. The high-pressure rotor drives the high-pressure compressor and turbine. Energy levels of uncontained fragments originating from each of these areas depends upon rotor speed, fragment mass, and the location (radially) of the center of gravity (c.g.) of the fragment. These parameters determine the fragment's initial translational (along its line of flight) and rotational velocities and kinetic energies, as shown in Eqs.2.1 and 2.2.

$$
\begin{gathered}
\mathrm{KE} \text { translational }=(1 / 2) \mathrm{mV}^{2}=(1 / 2) \mathrm{m}(\mathrm{r} \omega)^{2} \\
\mathrm{KE} \text { rotational }=(1 / 2) \mathrm{I} \omega^{2}
\end{gathered}
$$

where

$\mathrm{r}=$ distance from center of rotation to the fragment's center of gravity

$V=$ translational velocity of the fragment

$\mathrm{m}=$ fragment's mass

$\omega=$ rotational or angular velocity

$\mathrm{I}=$ mass moment of inertia. 


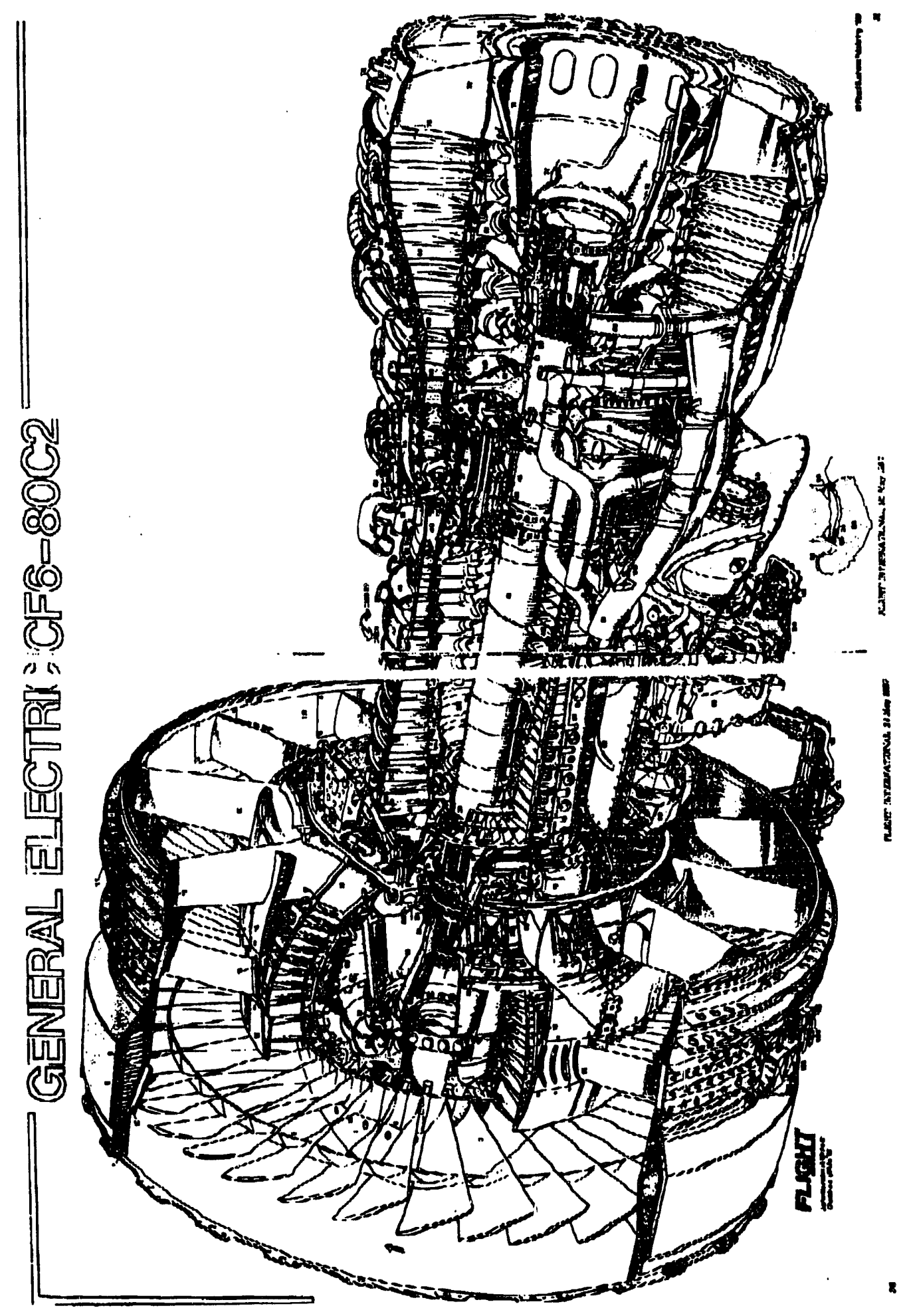

Figure 2.6 GE CF6-80C2 engine 


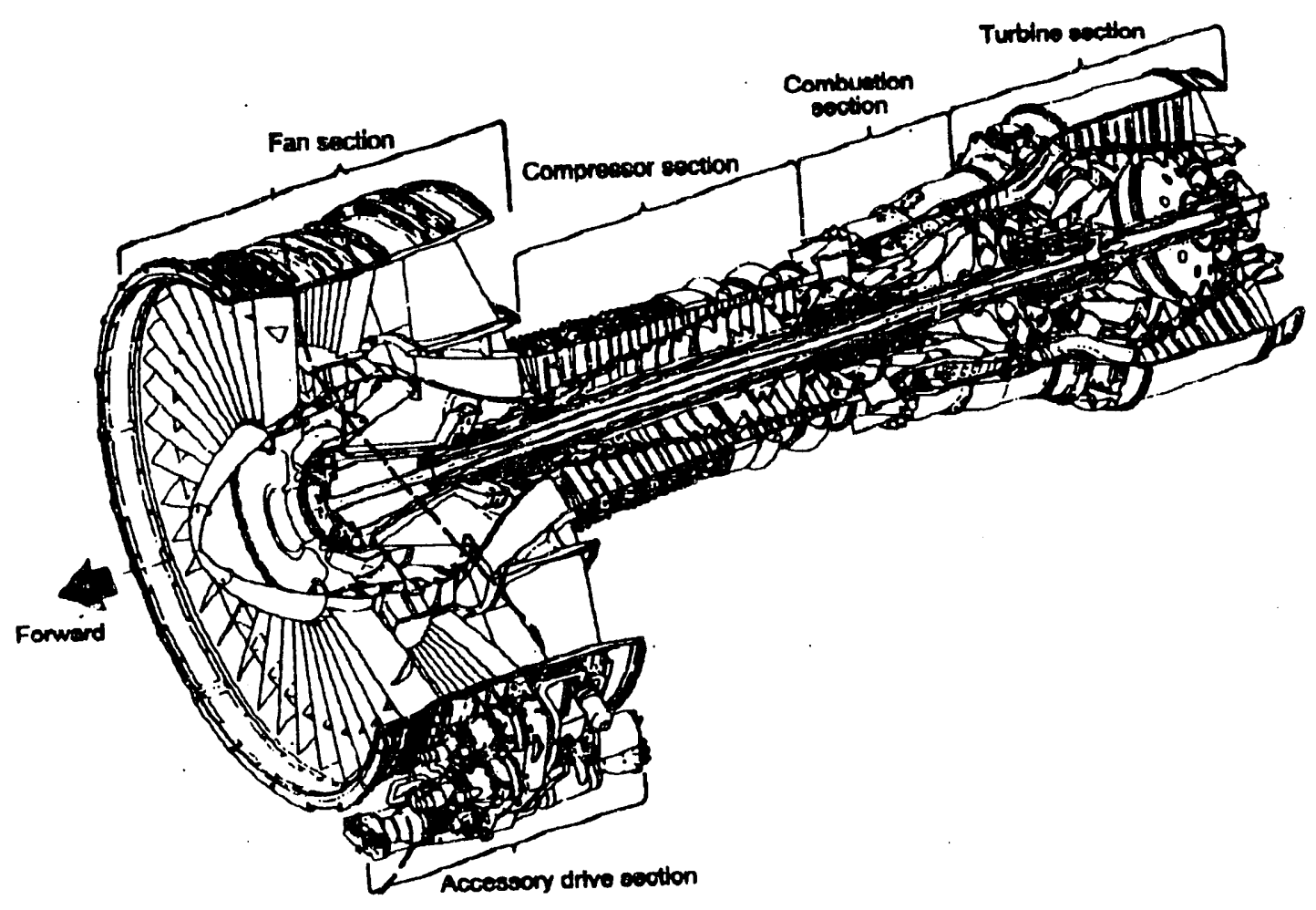

Figure 2.7 Gas turbine engine chambers (from similar CF6-6 engine) 


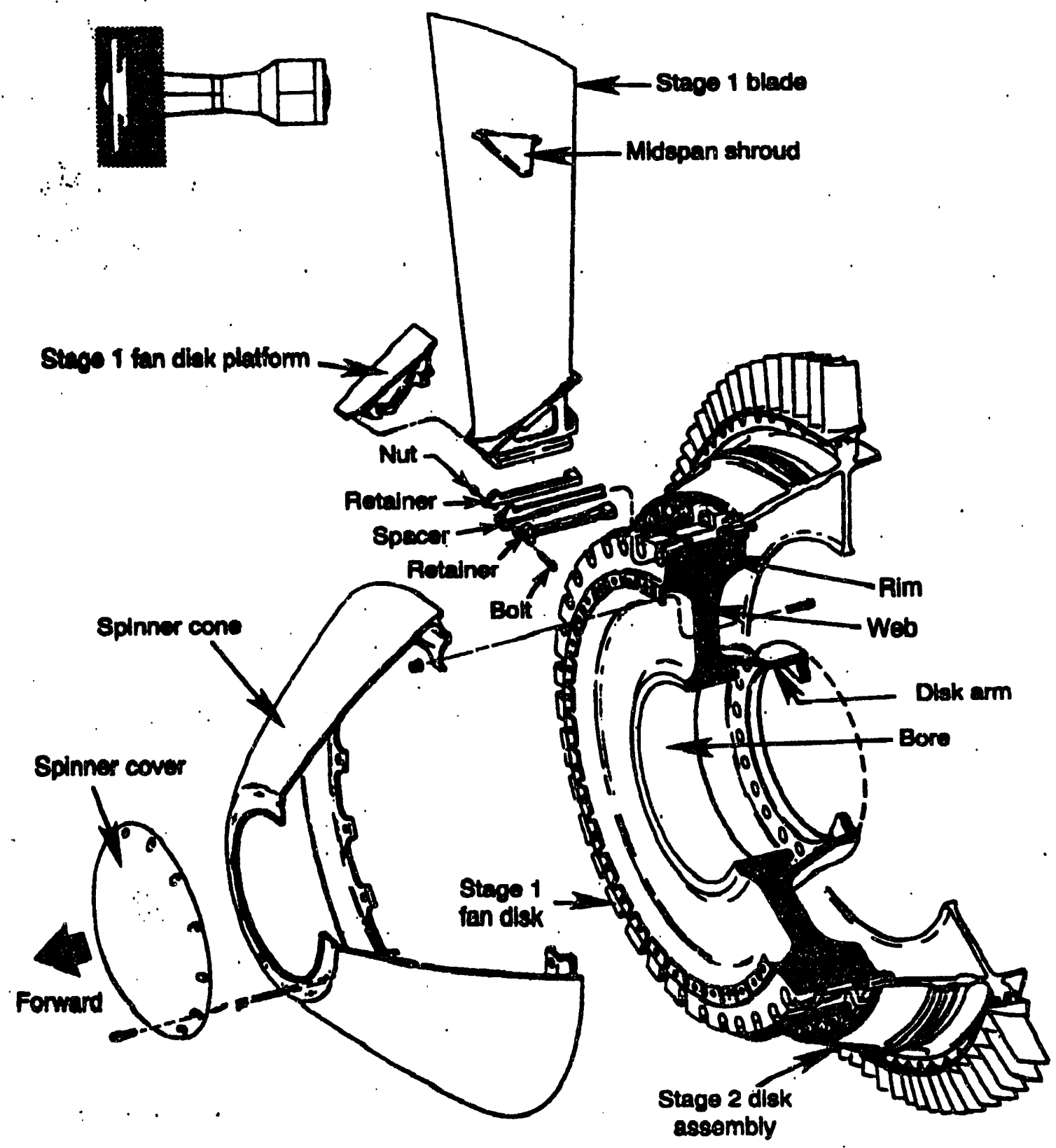

NOTE:Stage 1 fan dlsk highlighted

Figure 2.8 GE CF6-6 fan rotor assembly 


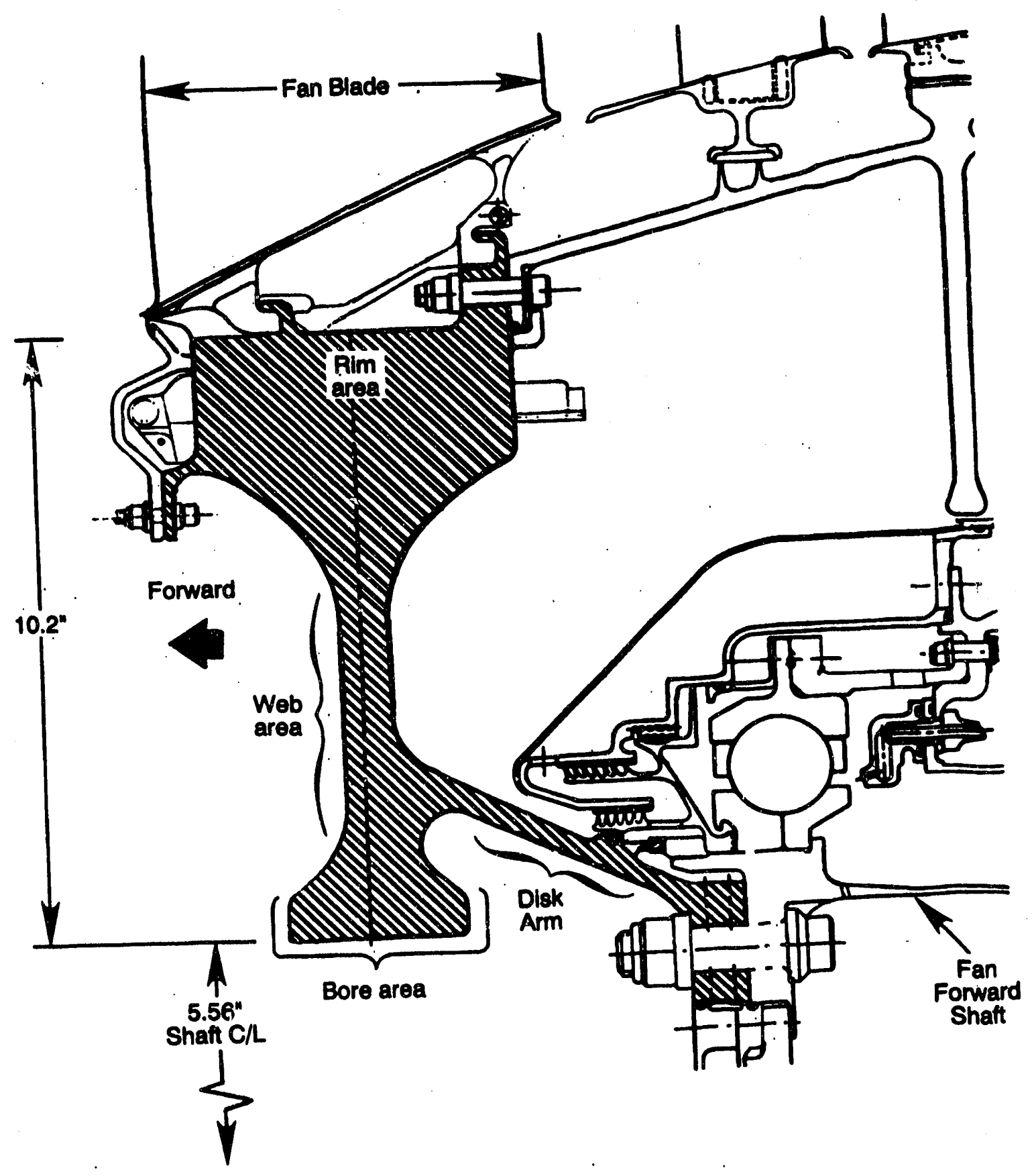

Figure 2.9 CF6-6 fan disk cutaway view 
Previous casing penetration studies have evaluated maximum kinetic energy fragments as worst case $[2,4,5,32,33]$. As shown in Figure 2.10, the translational component of energy is a maximum in the case of a bladed disk fragment when the included angle is $134^{\circ}$, or slightly greater than a $1 / 3$ section. Rotational energy increases with disk sector angle up to $360^{\circ}$ where all kinetic energy is in rotation and none translation, however, rotational energy of turbine disks has been shown to provide little contribution to penetrating ability [32,33]. In fact, it may decrease penetrating ability by offering a fragment surface of increased area. Further discussion of the contributions of rotational energy to a fragment's penetrating ability is presented in section 4 .

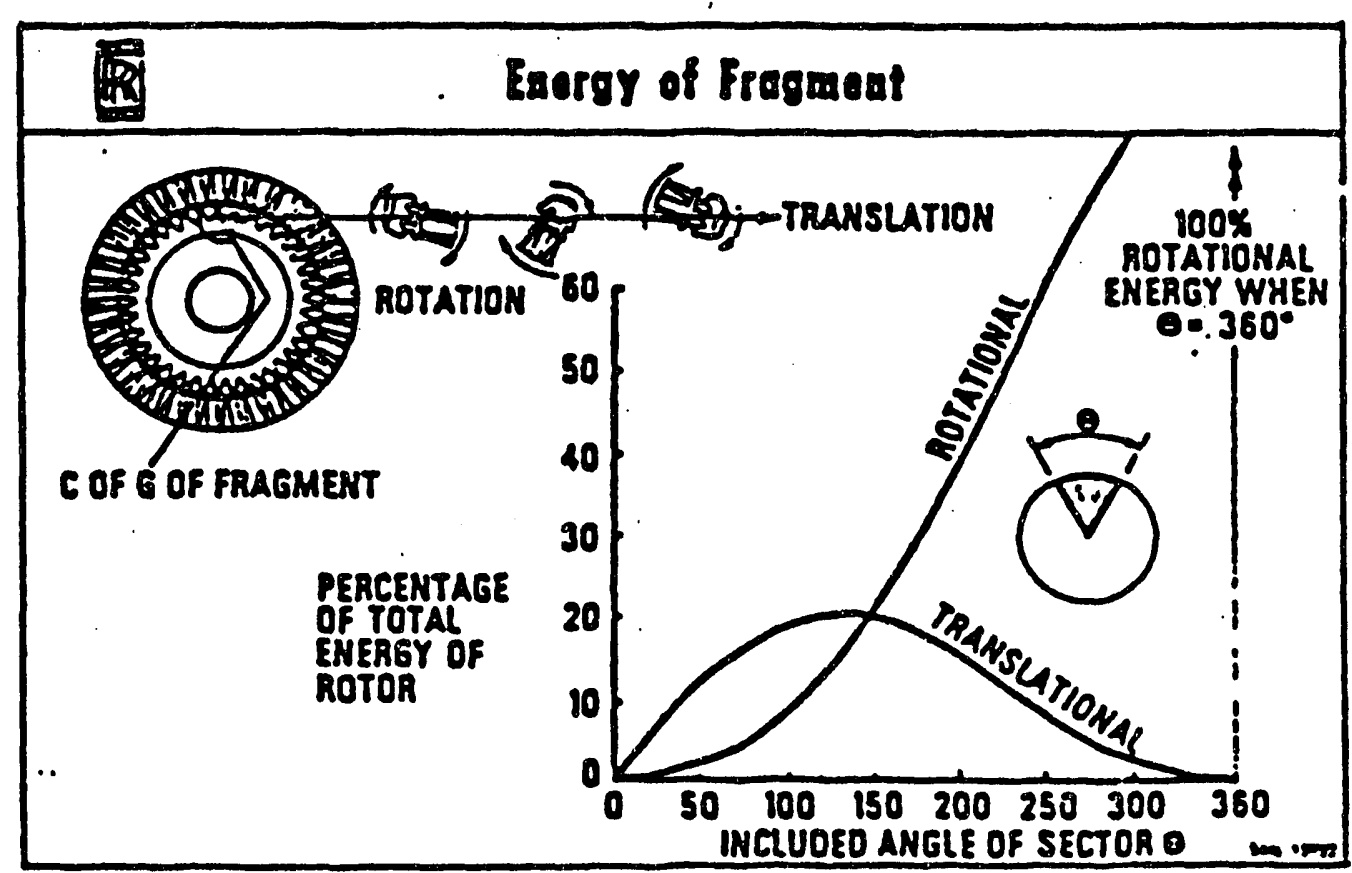

Figure 2.10 Rotational vs. translational disk energies [2]

Projected impact area, fragment mass and velocity, and impact angle are critical parameters in penetrations and perforations of metals [34-37]. This almost intuitive result of numerous studies and tests means that larger fragments require a greater energy to perforate the same thickness of a given material. The ratio of maximum kinetic energy to projected area can be used to roughly quantify penetrating abilities of various turbine engine fragments into generic on-board containers. These ratios have been determined for a number of different idealized fragments matching the 
descriptions of those derived from high- and low-cycle fatigue engine bursts, and for those historically to have existed as actual uncontained fragments. From Table 2.1, that shows these ratios and the corresponding fragments, fan blades, disk fragments, and rim sections, as well as high pressure turbine and compressor blades appear to have the greatest penetrating abilities.

Table 2.1 Pextetrating Abilities of Various Engine Fragments, or KE/A

\begin{tabular}{|c|c|c|c|c|c|c|c|}
\hline KE/A & $\begin{array}{c}1 / 3 \text { Fan } \\
\text { Disk }\end{array}$ & $\begin{array}{c}\text { 1/20 Fan } \\
\text { Disk }\end{array}$ & $\begin{array}{c}\text { Fan } \\
\text { Blade }\end{array}$ & $\begin{array}{c}\text { Fan } \\
\text { Rim }\end{array}$ & $\begin{array}{c}\text { HPC } \\
\text { Blade }\end{array}$ & $\begin{array}{c}\text { HPT } \\
\text { Blade }\end{array}$ & $\begin{array}{c}1 / 3 \text { HPT } \\
\text { Disk }\end{array}$ \\
\hline $\mathrm{lb}$ in $/$ in $^{2} \times 10^{6}$ & $(0.40)$ & $(0.067)$ & $\left(1.1^{\prime}\right.$ & $(2.3)$ & $(0.5)$ & $(0.96)$ & $(0.069)$ \\
\hline
\end{tabular}

A 1/3 high-pressure turbine disk was also evaluated, but since its kinetic energy was less than that of a fan blade and its projected area for penetration much greater, it was assumed to have a much lower penetrating ability than a fan blade

The kinetic energy-to-area ratios in Table 2.1 were calculated using each fragment's maximum redline translational release velocity (derived from 3,854 and 11,055 rpm, respectively, for the low- and high-pressure rotors). The actual engine speeds experienced by the GE CF6-80C2 engines during a 14-hour 747-400 intercontinental flight are shown in Figure 2.11 [45], as a percentage of a reference engine speed known as $N_{1}$. Numerically, $N_{1}$ is defined as $3280 \mathrm{rpm}$ for the low-pressure rotor on the CF6-80C2 engine. This means that $3854 \mathrm{rpm}$, or redline engine speed, is equivalent to $117.5 \%$ of $\mathrm{N}_{1}$. Figure 2.12 details the stages, power levels, and times at each power level for the same typical intercontinental cargo aircraft flight profile.

Note that the vast majority of flight time is spent at a power level of $102.3 \%$ of $\mathrm{N}_{1}$, or $87 \%$ of redline. This $13 \%$ reduction in velocity yields a $24 \%$ decrease in kinetic energy since $\mathrm{KE}$ is a function of the square of velocity. For conservatism, however, analyses and tests outlined in the following sections assume fragment release velocities associated with redline rotational rates. Engine casings are required to contain single blades with velocities associated with $120 \%$ of redline speed, or a moderate but rare overspeed event.

The General Electric CF6-80C2 engines are expected to have fewer rotor bursts than previous engines. Flight profiles are followed by the aircraft's flight computer, while numerous primary and back-up control systems prevent engine overspeed events (one of the many causes of rotor failures). This particular engine, therefore, is much less likely (although not quantifiably less) to experience an over-speed event than older engines. Additionally, no engine burst data has yet been published on this relatively new engine and no failures are known by Boeing to have occurred (at least up to early 1992). 


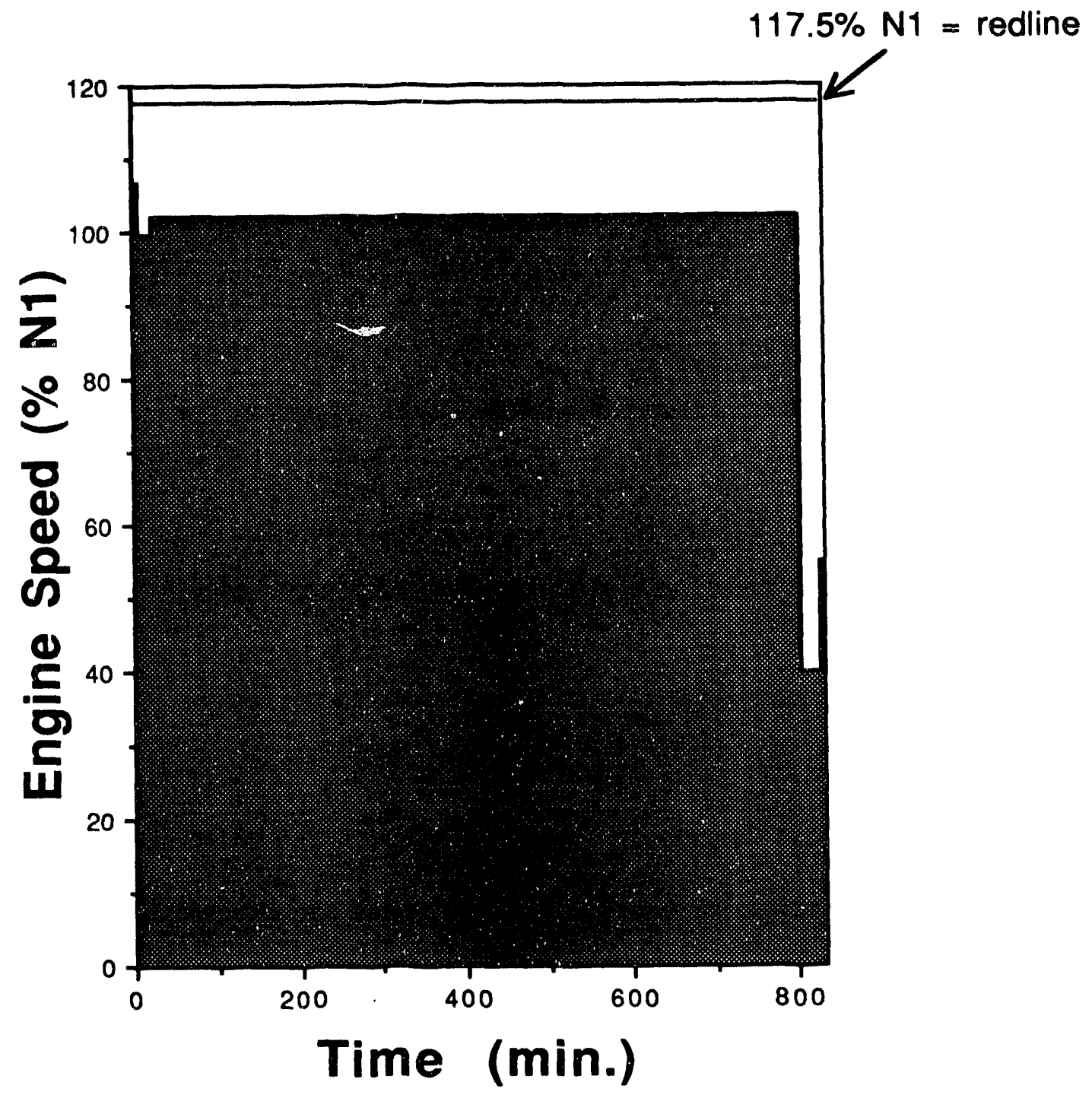

Figure 2.11 Typical intercontinental cargo aircraft flight profile $\left(\mathrm{N}_{1} \mathbf{v s .} \mathrm{t}\right)$ 


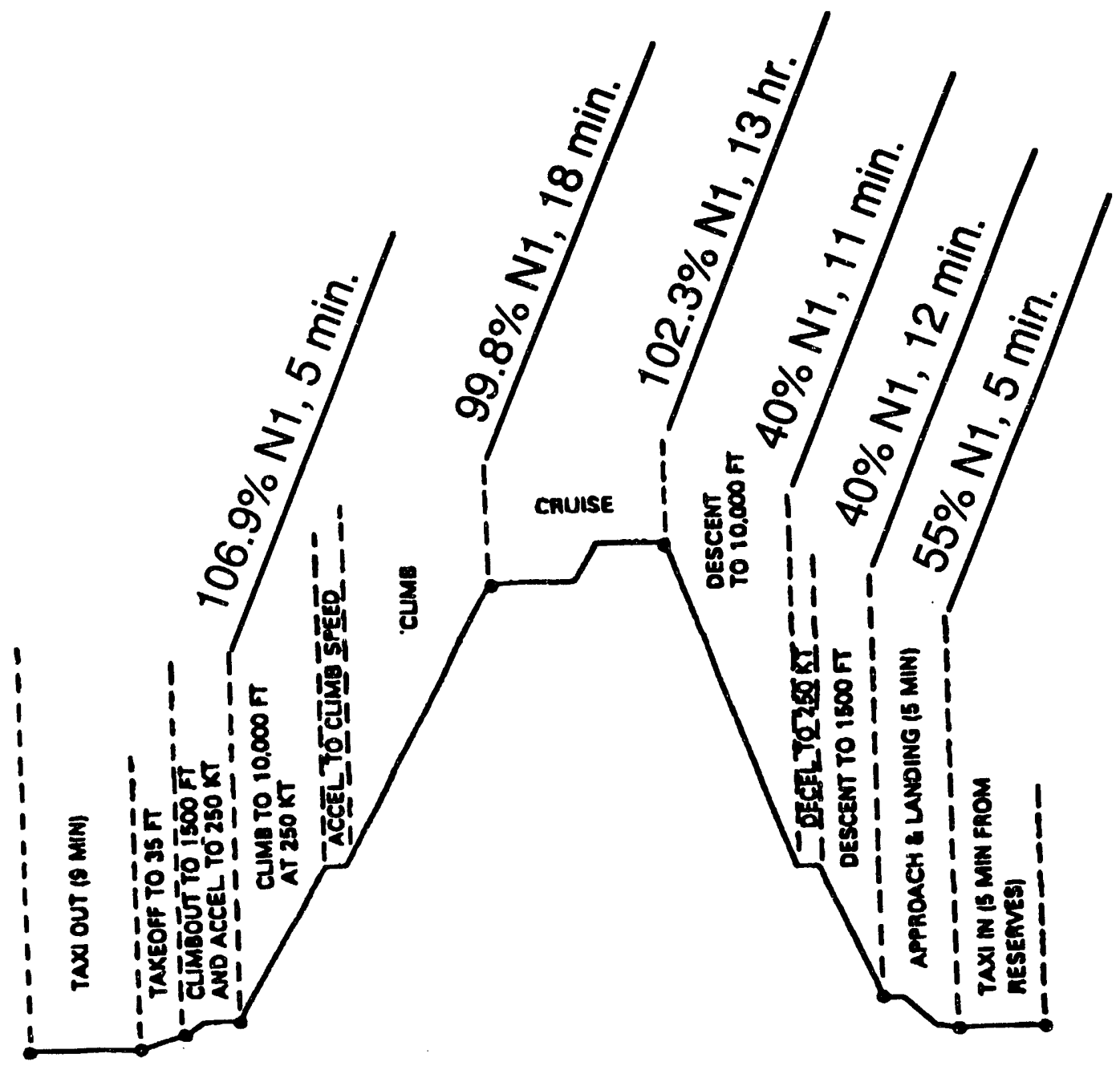

Figure 2.12 Typical intercontinental cargo aircraft flight profile

In terms of fragments' abilities to perforate the engine casing and become uncontained, only disk sections (including, possibly rim sections) are openly acknowledged by the engine manufacturer. The existence of uncontained individual blades in the literature, however, suggests that possibly disk fragments would provide a pathway through the casing for blades that would otherwise have been contained. Thus, all of the fragments that appear to have substantial penetrating abilities should be analyzed in greater detail, either with finite element analyses or penetration experiments, or both. 


\section{Probability Analysis}

An example loading configuration for a cargo aircraft for intercontinental transport of numerous generic containers is shown in Figure 3.1. Actual loading conditions would be based partially upon the load rating per square foot on the cargo deck, and on maximizing the number of generic containers per flight. Two different standard-sized cargo containers, $8 \mathrm{ft} \times 8 \mathrm{ft} \times 10 \mathrm{ft}$ and $8 \mathrm{ft} \times 8 \mathrm{ft} \times 20 \mathrm{ft}$, could be used to secure generc containers to the cargo deck. Equal spacing between generic containers was assumed, such that either the single or double cargo container could be used interchangeably. One proposed tie-down method inside these cargo containers is shown in Figure 3.2. These containers are locked to tracks recessed into the cargo deck. FAA regulations and NUREG-0360 [38] require that the tie-down system withstand $1.5 \mathrm{~g}$ 's sideward, $9 \mathrm{~g}$ 's forward, $2 \mathrm{~g}$ 's upward, and $4.5 \mathrm{~g}$ 's downward. Two rows of 14 packages, aligned end-to-end with 30 inch spacing between packages, are assumed. By assuming a maximum number of generic containers per flight, the probability analysis should be conservative.

A typical 14-hour intercontinental flight is assumed for the probability analyses. Major assumptions in terms of obstructions between the four generic engines and the packages on board the cargo aircraft include omission of wing support and fuselage structures including struts and skin. Although some form of wing support structure or skin are located directly in the path of two of the four engines, quantification of these structures' abilities to slow high-energy fragments is virtually impossible. Also, the thin aircraft fuselage skin is known to provide little resistance to penetration from fragments; it, along with any wing structures, is therefore neglected.

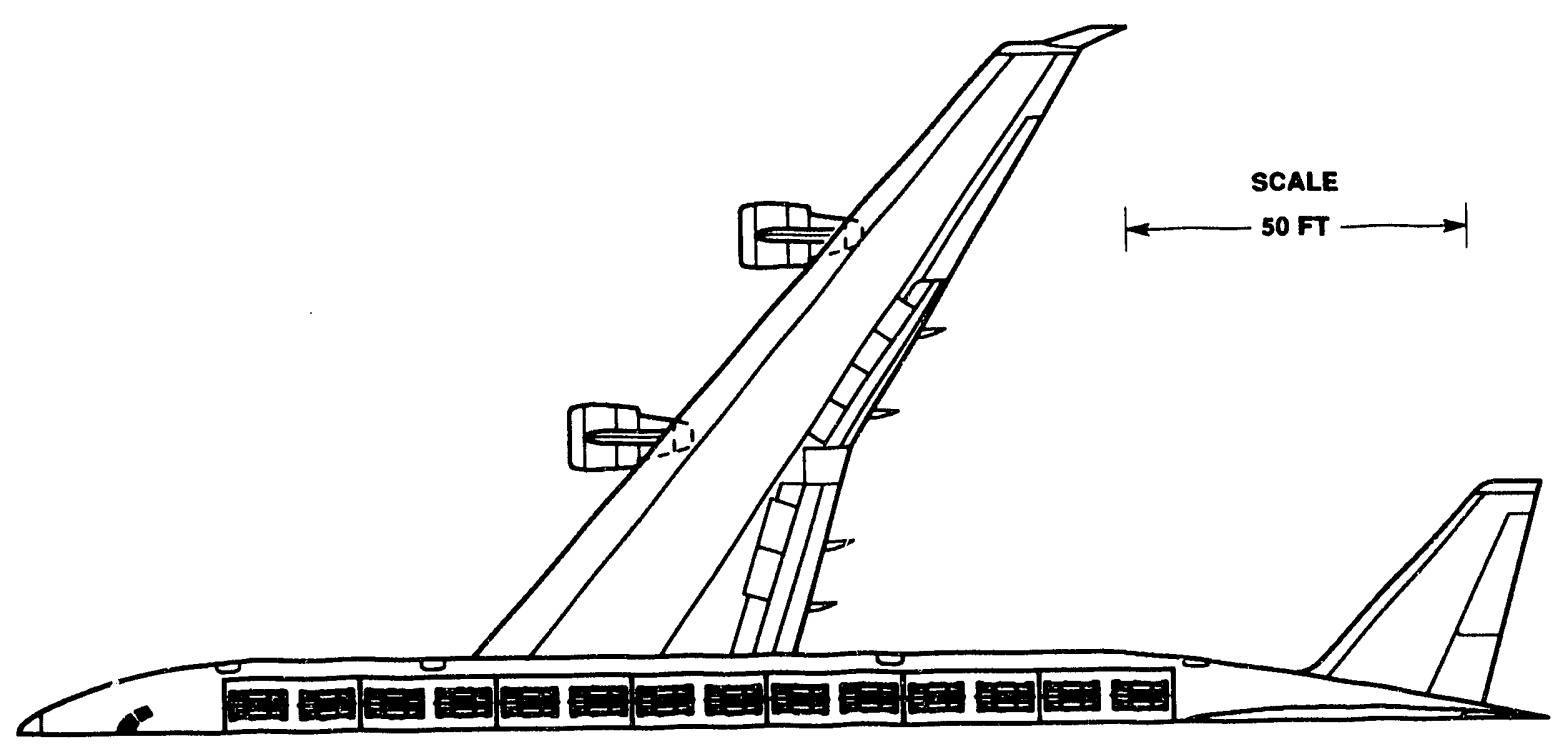

Figure 3.1 Fully-loaded cargo aircraft 


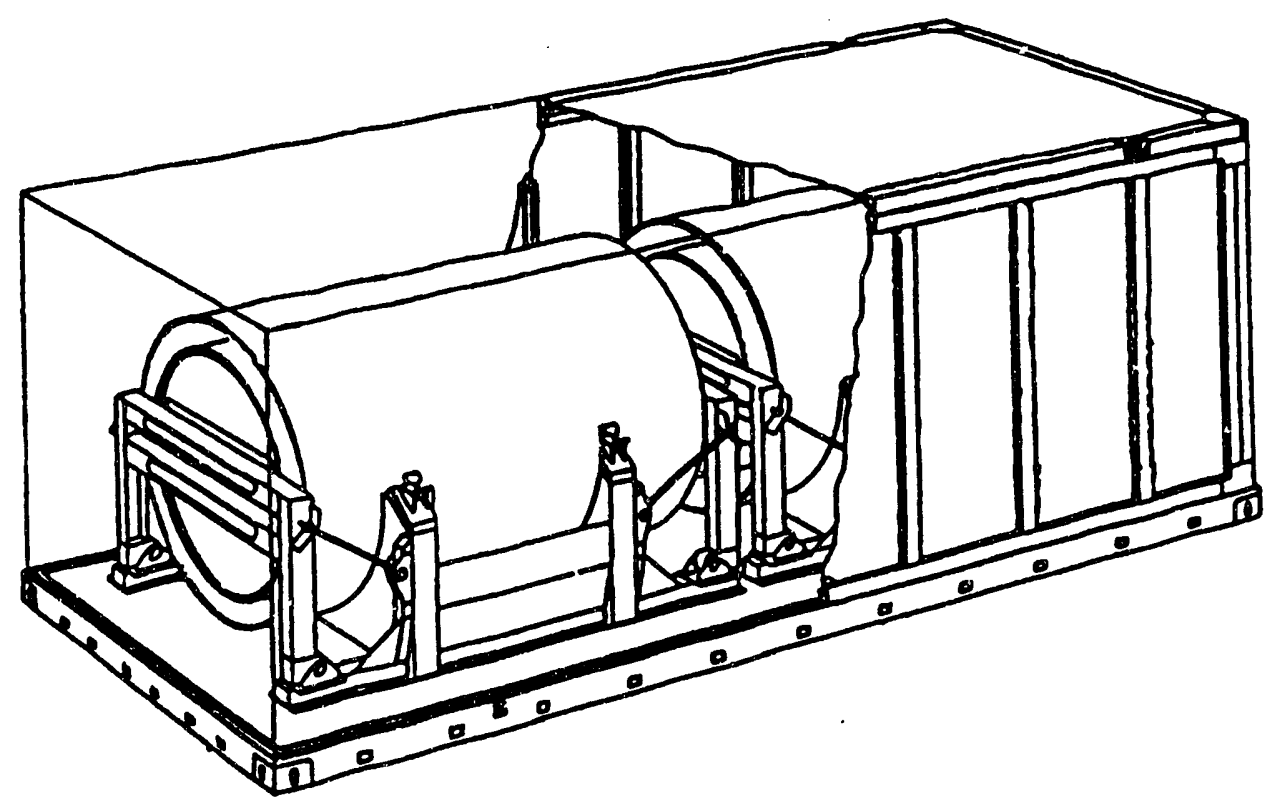

Figure 3.2 Generic air-transport container with tie-downs inside a cargo container

The probability of a jet engine fragment striking the primary containment vessel can be determined by the construction of an event tree. Figure 3.3 shows such an event tree for a $134^{\circ}$ fan disk fragment. The total probability of a $134^{\circ}$ fan disk section impacting the generic container's primary containment vessel is obtained by multiplying the successive probabilities of incidents leading to the impact, i.e., in this case, $P_{\text {toul }}=P_{1} \times P_{24} \times P_{3} \times P_{4} \times P_{5} \times P_{6}$. The individual event probabilities are detaled in the following sections. When multiplied out, $P_{\text {toul }}=9.18 \times 10^{-11}$ disk section impacts/hour. Similar total probabilities for fan blade and random fragment impacts are summarized in Table 3.1. Determinations of the values in this table are outlined in the following sections.

Table 3.1 Total Fragment Impact Probabilities $\left(\mathbf{P}_{\text {total }}\right)$

\begin{tabular}{|c|c|c|c|}
\hline & $134^{\circ} \mathrm{Fan}$ Disk & Fan Blade & Random Fragment \\
\hline (impacts/hour) & $9.18 \times 10^{-11}$ & $2.92 \times 10^{-10}$ & $1.21 \times 10^{-9}$ \\
\hline $\begin{array}{c}\text { (1 impact per number } \\
\text { of flights) } \\
\text { (14 hours/flight) }\end{array}$ & $778,000,000$ & $245,000,000$ & $58,900,000$ \\
\hline
\end{tabular}




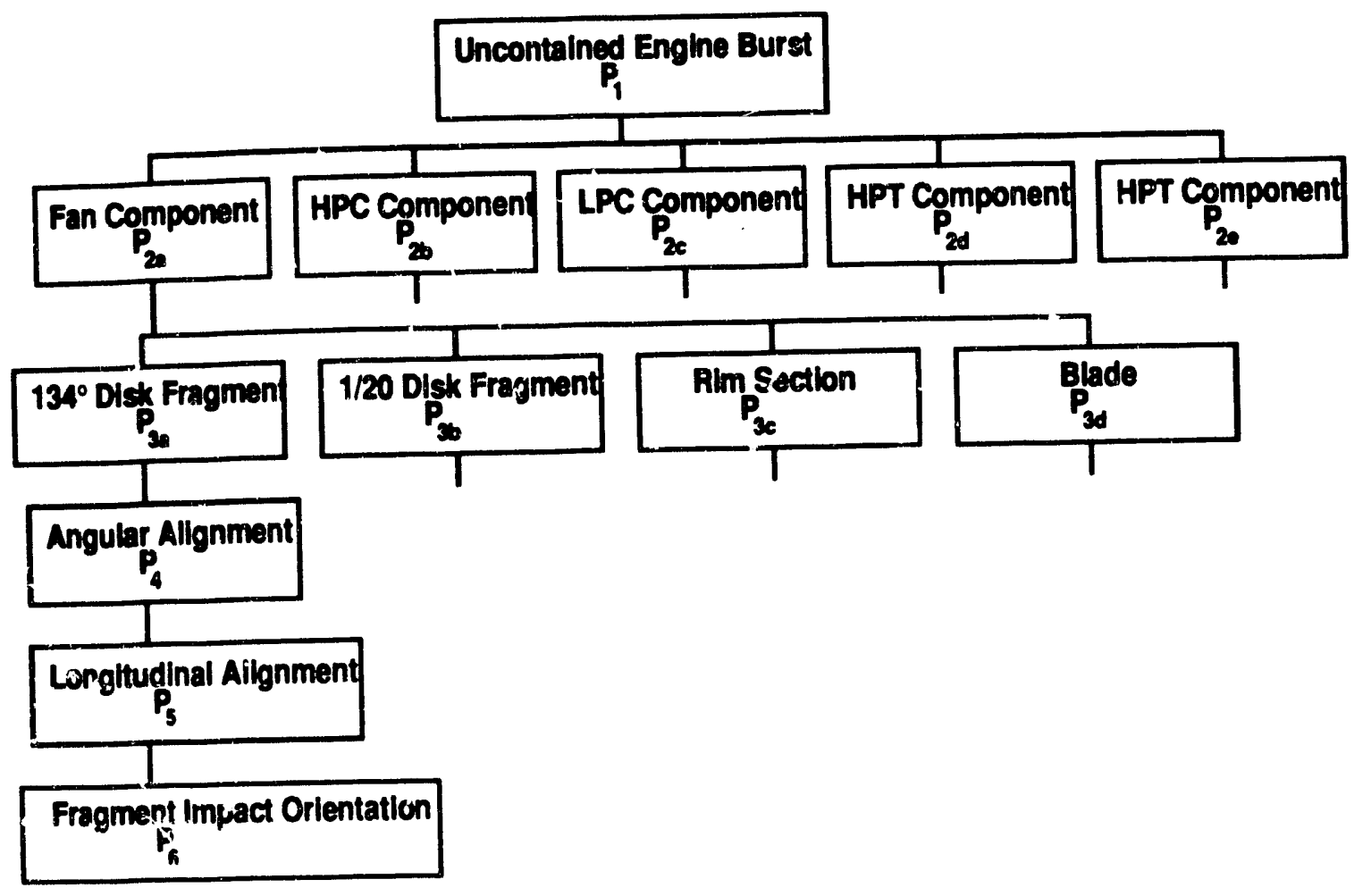

Figure 3.3 Fan disk impact probability event tree showing dominant branches

\subsection{Uncontained Failure Probability}

Statistics on aircraft gas turbine engine rotor failures that occurred in U.S. commercial aviation during the period from 1962 through 1986 are shown in Figure 3.4 [7]. These are compiled by the Federal Aviation Administration of the U.S. Department of Transportation. Statistics from years 1987 to present have not yet been compiled and published. U.S. failure rates are used in these analyses (instead of international rates) because of the greater detail in the U.S. literature. Data from modern high-bypass ratio jet engines from 1976 to 1986 are used in this analysis since the failure rates have been relatively constant during this most recent period. Table 3.2 provides the breakdown of uncontained rotor burst incidents by fragment type and rotor component for this eleven year period. In general, blades were the most commonly generated fragment type and the turbine section of the engine generated the largest number of these fragments. 


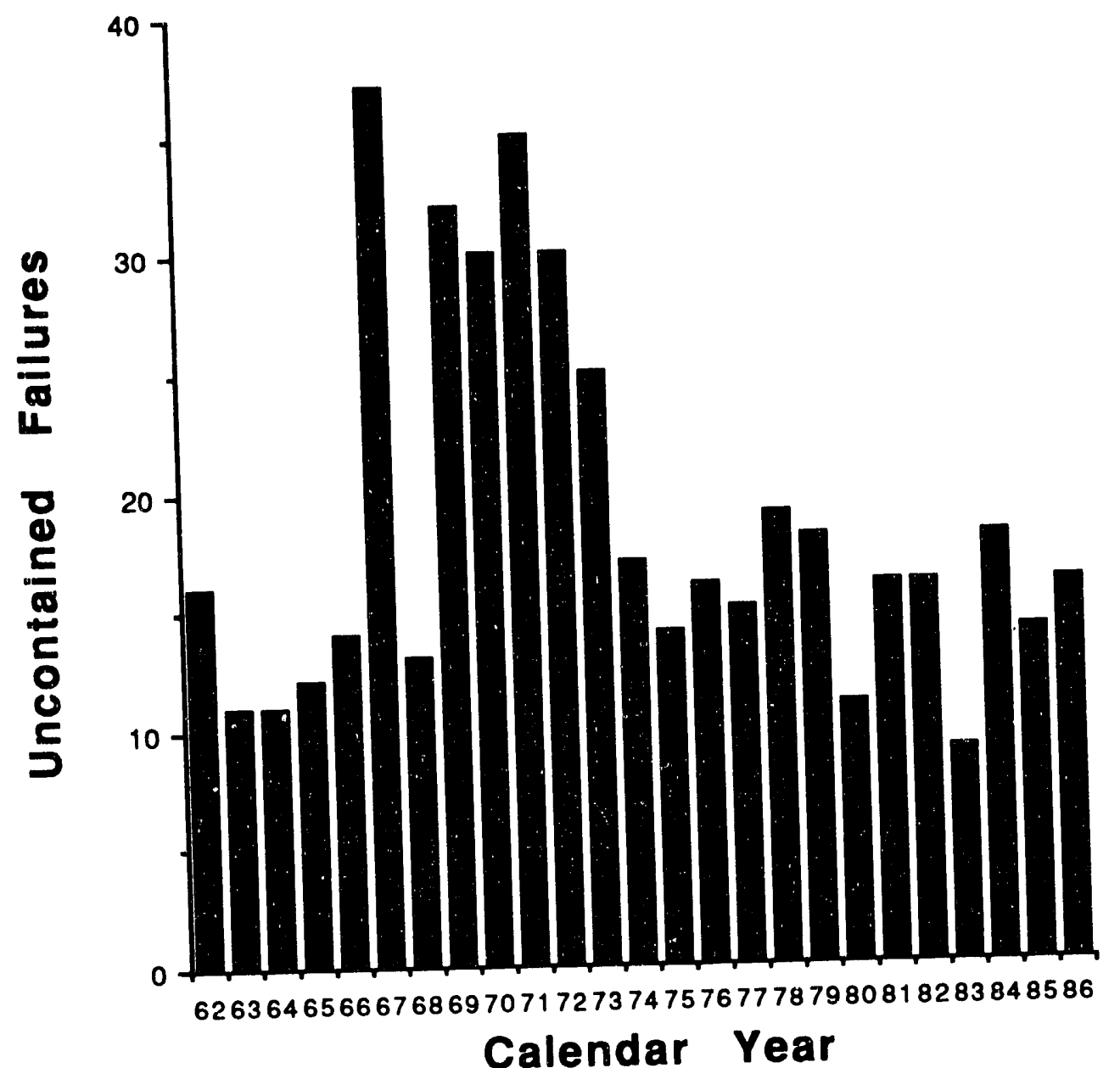

Figure 3.4 Uncontained gas turbine engine failures, 1962-1986

Table 3.2 U.S. Uncontained Engine Rotor Failure Incidents: 1976-1986

\begin{tabular}{|c|c|c|c|c|}
\hline \multicolumn{5}{|c|}{ Engine Rotor Component } \\
\hline Type Generated & Fan & Compressor & Turbine & Total \\
\hline Disk & 2 & 10 & 25 & 37 \\
\hline Rim & 0 & 7 & 1 & 8 \\
\hline Blade & 33 & 27 & 52 & 112 \\
\hline Seal & 1 & 4 & 7 & 12 \\
\hline Total & 36 & 48 & 85 & 169 \\
\hline
\end{tabular}


The uncontained failure rates (per million engine operating hours) in 1986 for various gas turbine engine rotor components are listed in Table 3.3. A total of 28.6 million aircraft engine operating hours were logged in 1986. Often, it is desirable to use the most recent data available to conduct probability analyses. However, Tables 3.2 and 3.3 indicate that since the total number of incidences is extremely low, a larger span of data is required for statistical significance.

Table 3.3 U.S. Uncontained Rotor Failures By Fragment Type in 1986 (per $10^{-6}$ engine operating hours) [7]

\begin{tabular}{|c|c|c|c|}
\hline Fragment Type & Fan Rotor & Compressor Rotor & Turbine Rotor \\
\hline Disk & 0 & 0 & $6.99 \times 10^{-2}$ \\
\hline Rim & 0 & $3.48 \times 10^{-2}$ & 0 \\
\hline Blade & $6.99 \times 10^{-2}$ & $3.48 \times 10^{-2}$ & $2.44 \times 10^{-1}$ \\
\hline Seal & 0 & 0 & $1.05 \times 10^{-1}$ \\
\hline Total & $6.00 \times 10^{-2}$ & $6.99 \times 10^{-2}$ & $4.19 \times 10^{-1}$ \\
\hline
\end{tabular}

The total uncontained fragment generation rate data in Table 3.4 is used to calculate a total uncontained failure rate per flight of $9.7 \times 10^{-6}(0.693$ uncontained failure/106 hours multiplied by an estimated 14 hours/flight). This value is $P_{1}$ in the probability event tree. Table 3.4 further breaks down the numbers of uncontained fragments by rotor component and fragment type for all turbofan engines, and solely CF6-series (CF6-6 and CF6-50) engines. The greater value between the average CF6-series uncontained failure rate and the rate for all gas turbine engines is used in the probability analyses for both conservatism and the fact that no data exist on the new GE CF6$80 \mathrm{C} 2$ high-bypass engine (introduced in 1987).

It is interesting to note that the majority of uncontained fragments are blades only, which are required by the FAA to be contained, at least in single blade form. The only data beyond 1986 (that was published in 1990), is that from the United Airlines Flight 232 Sioux City, Iowa, crash on July 19, 1989. An uncontained fan disk failure led to the accident [27]. So even though the data in Table 3.4 for CF6 engines show no incidence of compressor and fan disk, rim, or seal uncontained failures, they should be considered as possibilities.

The FAA rates used in this analysis were compiled in both per-mile and per-hour formats, although the per-hour format was used. These rates are likely conservative when applied to the current analysis since they were derived from generally much shorter flight lengths than one intercontinental flight, which would take approximately 14 hours. Not shown in these tables is the fact that over 60 percent of uncontained releases occur during taxi, takeoff, and landing, that combine for only a small fraction of the 14-hour flight [7]. 
Table 3.4 Average of 1976-1986 Uncontained Fragment Generation Rates $\left(\times 10^{-9}\right.$ incidents/hr) [7-17]

\begin{tabular}{|c|c|c|c|c|}
\hline \multicolumn{5}{|c|}{ All Gas Turbine Engines } \\
\hline & Fan & Compressor & Turbine & Total \\
\hline Disk & 8.2 & 41 & 103 & 152.2 \\
\hline Rim & 0 & 28.7 & 4.1 & 32.8 \\
\hline Blade & 135 & 111 & 213 & 459 \\
\hline Seal & 4.1 & 16.4 & 28.7 & 49.2 \\
\hline Total & 147.3 & 197.1 & 348.8 & 693.2 \\
\hline \multicolumn{5}{|c|}{ GE CF6-Series Engines } \\
\hline Disk & 0 & Compressor & Turbine & Total \\
\hline Rim & 0 & 0 & 106 & 106 \\
\hline Blade & 212 & 106 & 0 & 106 \\
\hline Seal & 0 & 530 & 318 & 1060 \\
\hline Total & 212 & 0 & 0 & 0 \\
\hline
\end{tabular}

Probabilities for uncontained bursts consisting of specific components $\left(\mathbf{P}_{2 a}, \mathbf{P}_{2 b}, \mathbf{P}_{2 a}\right.$, etc. $)$ are obtained from the ratios of component rate totals to the overall rate total. For example, the fan component release probability, $P_{2 a}$, is equal to $147.3 / 693.2=0.212$. Similarly for the fragment type (for a given component) probability, the fan blade release probability during an uncontained burst, $P_{3 \mathrm{~d}}$, is equal to $212 / 212=1.0$. Remember, the greater value from eitlier of the two tables in Table 3.4 is used in the calculation; thus, the probabilities within the third level in Figure 3.3 may add to a value greater than 1.0.

The first three levels of probabilities multiplied together $\left(P_{1} \times P_{2} \times P_{3}\right)$ are identical to the maximum values in the respective columns and rows of Table 3.4. Only $P_{34}$ and $P_{36}$ differ in that factors of 0.33 and 0.66 multiply the value of a specific component disk release probability $[2,25]$. Therefore, release rate for uncontained $134^{\circ}$ fan disk fragments is $8.2 \times 10^{-9} \times 0.33=2.73 \times 10^{-9}$ incidents/hour. For uncontained $1 / 20$ fan disk fragments, the rate is $8.2 \times 10^{-9} \times 0.66=5.47 \times 10^{-9}$ incidents/hour. Similarly, for uncontained fan blades, the rate is $212 \times 10^{-9}$ incidents/hour, etc., as shown in Table 3.5. Incidents/flight probabilities can be obtained by multiplying the tabular data by 14 hours/flight.

Table 3.5 Sample Uncontained Fragment Probabilities, $\mathbf{P}_{\mathbf{1}} \times \mathbf{P}_{\mathbf{2}} \times \mathbf{P}_{\mathbf{3}}\left(\times 10^{-9}\right.$ incidents/hr $)$

\begin{tabular}{|c|c|c|c|}
\hline $\mathrm{P}_{1} \times \mathrm{P}_{2 \mathrm{a}} \times \mathrm{P}_{3 \mathrm{a}}$ & $\mathrm{P}_{1} \times \mathrm{P}_{2 \mathrm{a}} \times \mathrm{P}_{3 \mathrm{~b}}$ & $\mathrm{P}_{1} \times \mathrm{P}_{2 \mathrm{a}} \times \mathrm{P}_{3 \mathrm{c}}$ & $\mathrm{P}_{1} \times \mathrm{P}_{2 \mathrm{a}} \times \mathrm{P}_{3 \mathrm{~d}}$ \\
\hline 2.73 & 5.47 & $0^{\mathrm{a}}$ & 212 \\
\hline
\end{tabular}

a. No incidences of uncontained fan rim sections in 1976-1986 U.S. commercial aircraft flight data. 


\subsection{Geometric Probability}

The geometric probability consists of four terms:

(1) angular probability

(2) longitudinal probability

(3) number of fragments

(4) number of engines.

Actual fragment dimensions are used in determining angular and longitudinal impact probabilities. The number of fragments is implied to be one each, corresponding to the uncontained release rates in Table 3.4. Releases have occurred with multiple fragments, but this level of detail is not present in the FAA data. The number of engines is four, but each engine yields a different angular probability due to its direction of rotation and distance from the fuselage, as illustrated in Figure 3.5. Two columns of packages running the length of the aircraft, equally spaced 30 inches apart in standard 10- or 20-ft cargo containers were assumed for the example analysis.

\subsubsection{Angular}

The angular probability is calculated on the assumption that the fragments are distributed randomly over $360^{\circ}$. Any fragment contact made with the primary containment vessel is assumed to be a potentially dangerous impact. Realistically, direct impacts by fragments normal to the surface of the containment vessel would present a much greater penetration threat than those that merely glance off of the top or bottom rounded surface. Thus, based on this conservative assumption, the diameter of the fragment (in the plane of the upper diagram of Figure 3.5) affects the angular probability.

The numerical value of the angular probability for each engine is determined by the ratio between the angle of possible fragment/primary containment vessel contacts and $360^{\circ}$. The possible impact angles for the c.g.s of fan blades and disk fragments generated by each engine are shown in Figure 3.6, that assumes a counterclockwise engine rotation direction, as viewed from the back. These angles were measured from a scaled drawing of the example cargo aircraft with generic engines and respectively scaled fragment widths. Note that fragment orientation affects the angular probability, especially in the case of the blade fragments. The blade is assumed to impact end-on $\pm 5^{\circ}$ as a worst-case scenario. The inner, left engine (right, as viewed from front in Figure 3.5) angular fan blade impact probability is:

$$
P_{a 1, L}=(\text { fragment path angle }) / 360^{\circ}
$$



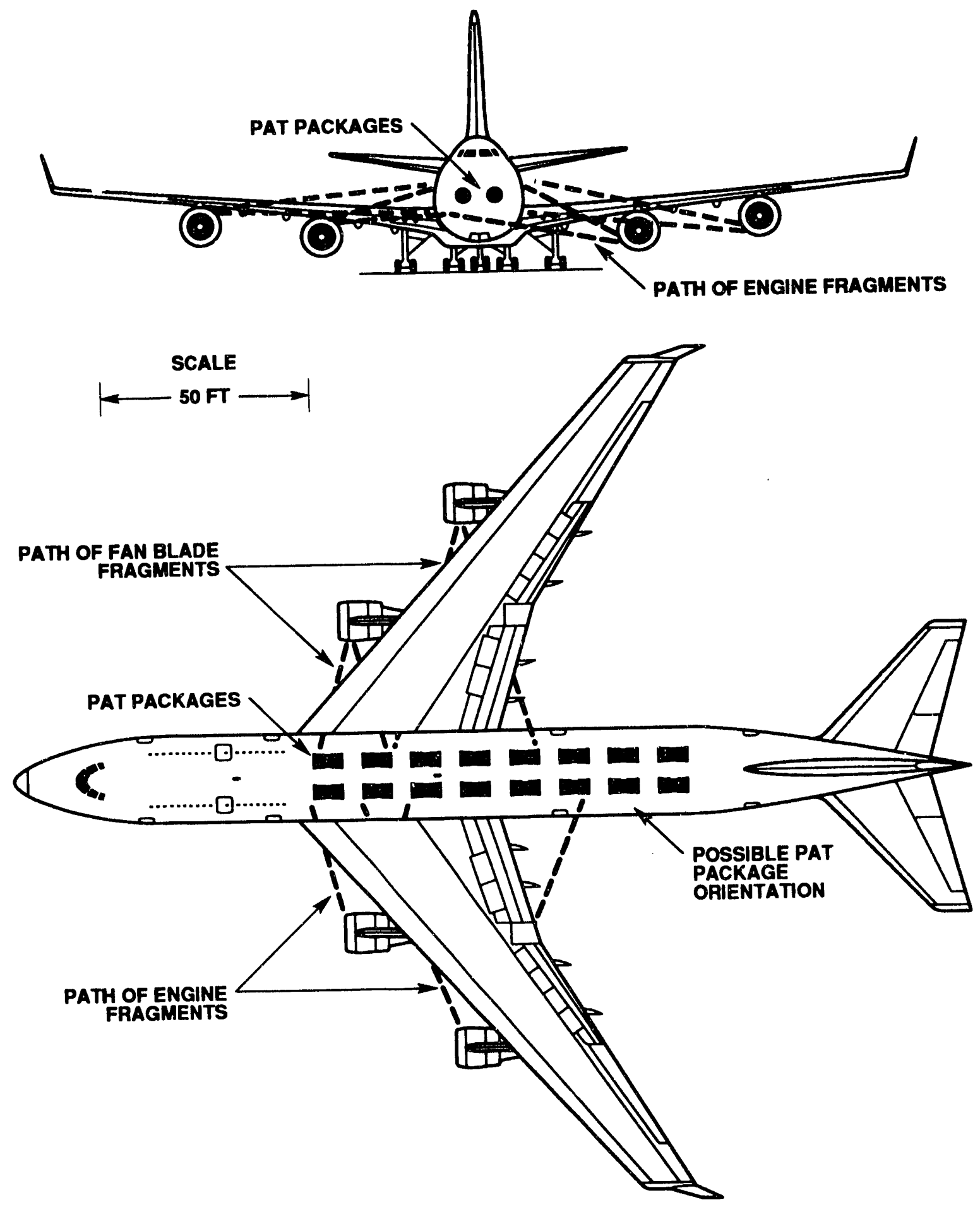

Figure 3.5 Angular and longitudinal engine fragment paths 
Since the fragment path angle, from the inner left engine, over which fan blade fragments could impact the primary containment vessel is $7.6^{\circ}$ (see Figure 3.6), $P_{a 1, L}=7.6 / 360=2.11 \times 10^{-2}$. The subscript " $a$ " denotes angular, " 1 " denotes inner engine (" 2 " for outer engine), and " $L$ " denotes left side of aircraft. Similarly, the other fan blade and disk fragment angular impact probabilities are shown below in Table 3.5.

Table 3.6 Angular Fragment-to-Primary Containment Vessel Impact Probabilities, $\mathbf{P}_{\mathbf{4}}\left(\times \mathbf{1 0}^{-2}\right)$

\begin{tabular}{|c|c|c|c|c|}
\hline & Inner,Left & Inner,Right & Outer,Left & Outer,Right \\
\hline Fan Blade & 2.11 & 1.67 & 0.917 & 0.778 \\
\hline Fan Disk & 2.69 & 2.39 & 1.25 & 1.14 \\
\hline
\end{tabular}




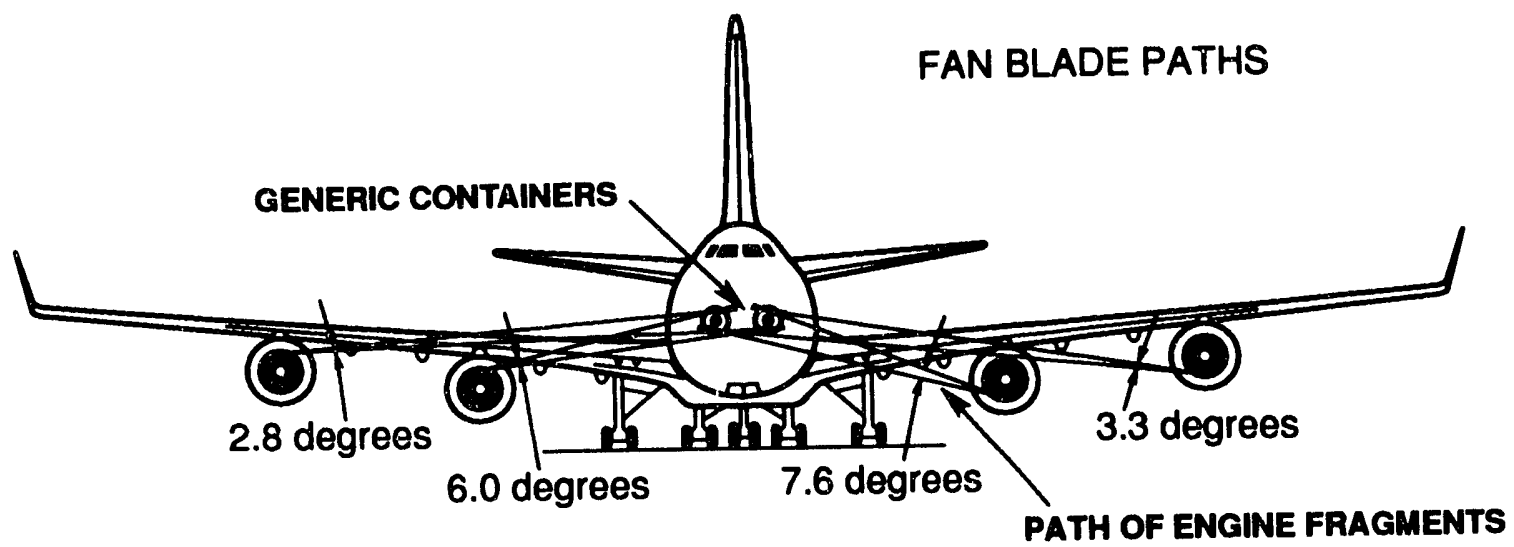

SCALE
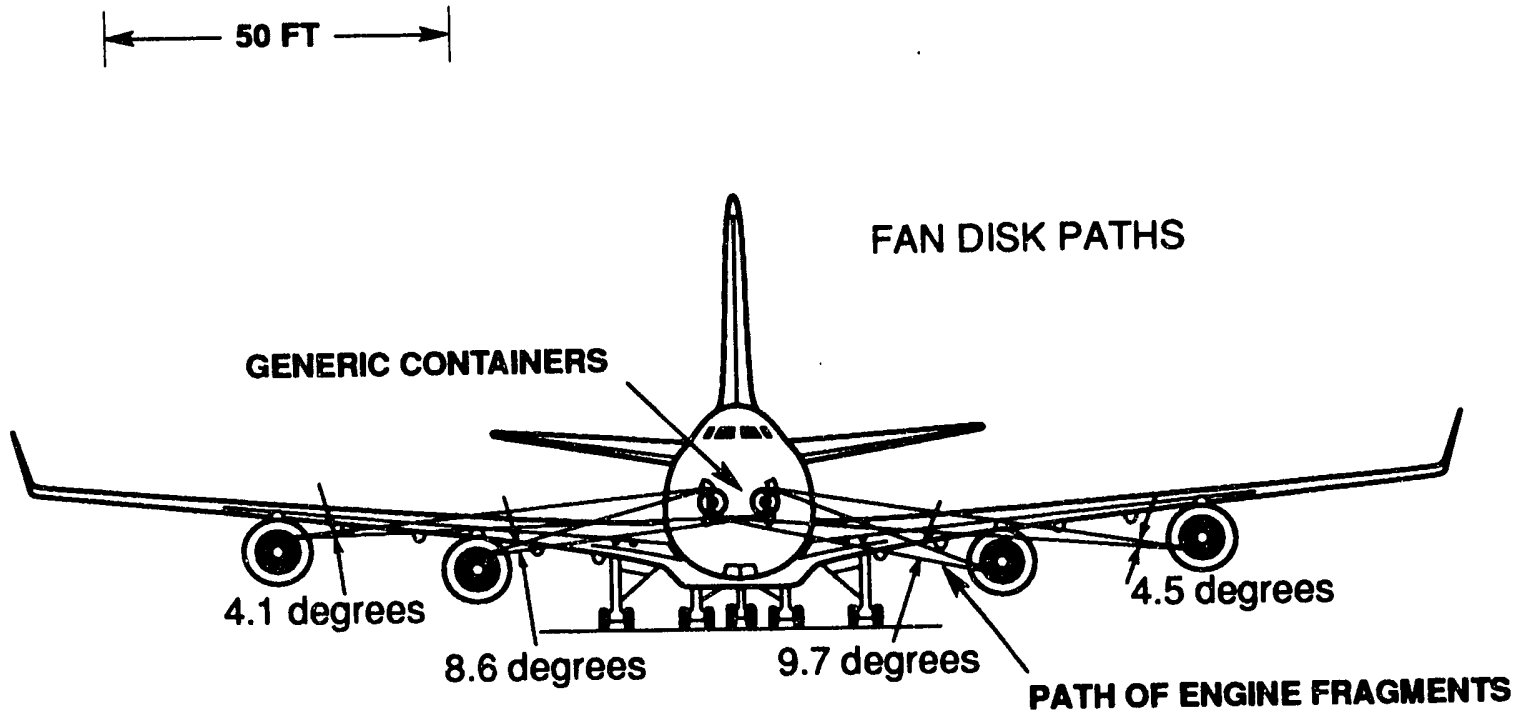

Figure 3.6 Fan blade and disk angular impact regions

\subsubsection{Longitudinal}

When a fragment penetrates an engine casing, it tends to be deflected in an axial or circumferential direction. Inspections of damage to surroundings caused by actual uncontained bursts show that heavy ( $>4 \mathrm{lbs}$ ) fragments tend to remain within $\pm 5^{\circ}$ of the rotor plane. Deflections up to about $33^{\circ}$ have been recorded with lighter fragments. The British Civil Aviation Authority (CAA) recommends the assumption of $\pm 3^{\circ}$ for disks and $\pm 5^{\circ}$ for the angular dispersion of all other fragments $[22,25]$. The FAA recommends $\pm 3^{\circ}$ for large disk sections, $\pm 5^{\circ}$ for medium and small- 
er disk sections and $\pm 15^{\circ}$ for all other fragments [21]. Since a wider distribution yields a more conservative estimate of engine fragment/generic container interaction probabilities, $a \pm 5^{\circ}$ angular dispersion for fan disk and blade sections and $\pm 15^{\circ}$ dispersion for all other fragments, is assumed for longitudinal probability determinations.

The longitudinal probability is determined from the ratio of the length of primary containment vessels within the spread of fragment paths to the length of fragment path spread. Figure 3.7 shows the c.g. paths of all possible engine component fragments from the primary fan through the low-pressure compressor at the rear of the engine. Both columns are shown in the half-aircraft figure to emphasize that either column could be struck by fragments depending upon the radial angular release location, as discussed in section 3.2.1, but longitudinally only the inner column of primary containment vessels could be impacted by fragments from the two engines shown in Figure 3.7. Heavier fragments, such as those generated by the primary stage fan, only have a spread of $\pm 5^{\circ}$, as shown in Figure 3.8. The longitudinal probability for fan fragments released from the inner engine, for example, is as follows:

$$
P_{L 1}=\left(N \times L_{c}+F \cdot W \cdot\right) /\left(2 D_{E 1} \tan 5^{\circ}+F \cdot W .\right)
$$

where

$\mathrm{N}=$ number of primary containment vessels in fragment path per column

$\mathrm{L}_{\mathrm{c}}=$ length of primary containment vessel

F.W.=fragment width

$\mathrm{D}_{\mathrm{E} 1}=$ distance from inner engine centerline to container column centerline 


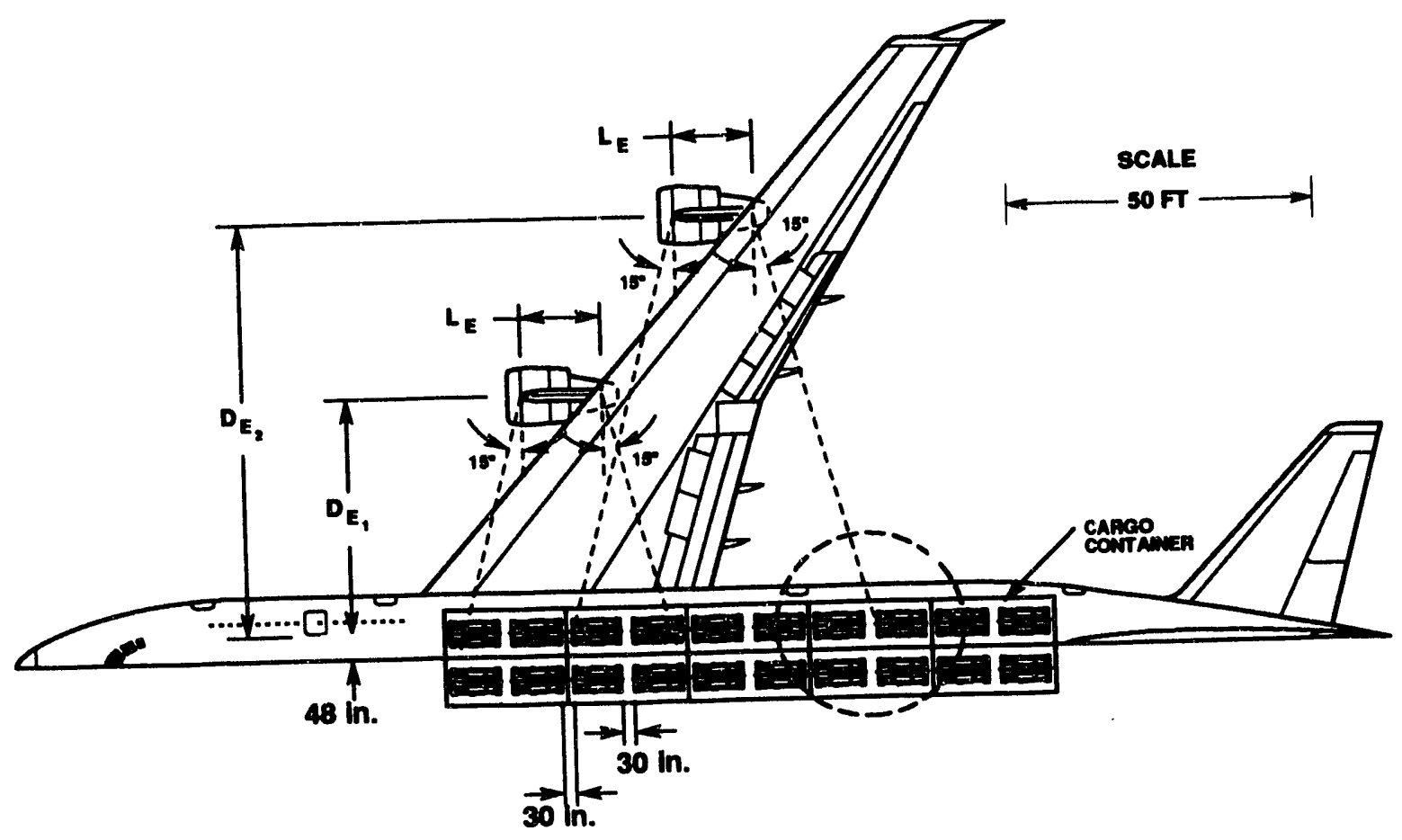

Figure 3.7 Longitudinal fragment impact regions (all frags.)

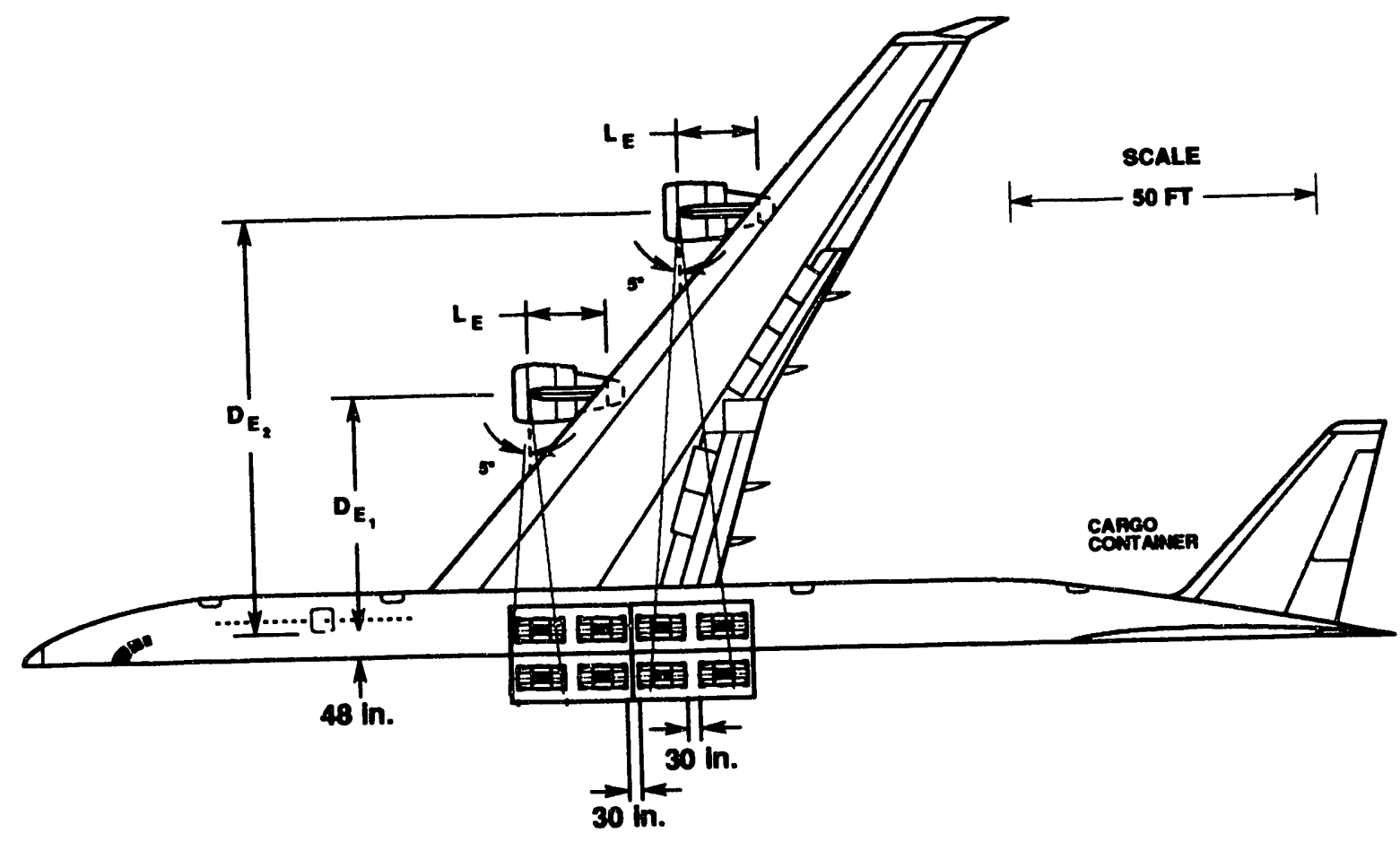

Figure 3.8 Longitudinal fan component impact regions 
The example length of the primary containment vessel, $\mathrm{L}_{c}$, is assumed to be 31 inches, the fan blade width, F.W., is 6.8 in., $\mathrm{D}_{\mathrm{E} 1}$ is 430 inches, and $\mathrm{N}$ is 1.0 primary containment vessels in the case illustrated in Figure 3.8. Since a fragment could impact either column of packages, depending upon the release angle, the column resulting in the greater longitudinal probability is chosen for conservatism. This means that $D_{\mathrm{E} 1}$ could be equal to 430 inches or $430+96$ inches, with $N$ possibly changing as well, depending on which resulted in a greater $P_{5}$. Table 3.6 lists the longitudinal impact probabilities for fan blades and disks, and all engine fragments.

Table 3.7 Longitudinal Fragment-to-Primary Containment Vessel Impact Probabilities, $\mathbf{P}_{5}$

\begin{tabular}{|c|c|c|}
\hline & Inner Engine & Outer Engine \\
\hline Fan Blade & 0.461 & 0.435 \\
\hline Fan Disk & 0.458 & 0.434 \\
\hline Random Fragment & 0.329 & 0.280 \\
\hline
\end{tabular}

The fragment path angle for the general category of "all fragments" is $\pm 15^{\circ}$. A "worst-case" PAT loading location is assumed for each probability calculation (with the 30 -inch package spacing) in order to conservatively maximize the resulting probability value. The length of the engine is added to the denominator of Eq. 3.2 to take into account the fact that the c.g.s of "random fragments" do not emanate from a single point in the plane, as in the case of fan fragments, but from the entire length of the engine. The longitudinal probability equation thus becomes:

$$
P_{L 1}=\left(N \times L_{c}+F \cdot W \cdot\right) /\left(L_{E}+2 D_{E_{1}} \tan 15^{\circ}+F \cdot W .\right)
$$

The combined geometric fragment-to-primary containment vessel probability for individual fragments is the sum of the product of angular and longitudinal probabilities per engine:

$$
P_{4} \times P_{5}=\left[\left(P_{a 1, \mathbb{R}} \times P_{11}\right)+\left(P_{a 2, \mathbb{R}} \times P_{12}\right)+\left(P_{a 1, L} \times P_{11}\right)+\left(P_{a 2, L} \times P_{12}\right)\right]
$$

\subsection{Fragment Orientation}

Due to the rotational energies of uncontained jet engine fragments, the orientation of some specific fragments during impacts with generic containers (as well as the engine casing and wing and fuselage structures) can greatly affect potential abilities for perforation or penetration. Blades, for example, have much greater penetrating ability in an "end-on" impact orientation than a "side-on" impact, where the penetrating area is larger. This is true for all fragments with a large aspect ratio, or length-to-width ratio. Blades, 1/20 disk fragments, and rim sections are assumed to have penetrating ability when impacting normal to a package surface $\pm 5^{\circ}\left(10^{\circ}\right.$ total), based 
upon rotational vs. translational energy of these fragments and the fragments' tendencies to slap down during oblique impact. Since both ends of each of these fragments have small penetrating areas, the probability that a given fragment is in a penetrating orientation is given by the following equation:

$$
P_{6}=(2 \text { ends }) \times\left(10^{\circ} / 360^{\circ}\right)=0.055
$$

More uniformly-shaped fragments, such as a $1 / 3$ disk fragment are less likely to have such a quantifiable orientation that increases penetrating ability. Therefore, the fragment orientation probability is one, i.e., $P_{6}=1.0$. Most other fragments, whose penetrating abilities are known to be lower than fan blades and disks, are assumed to need optimal orientation for even a chance of penetration. Therefore, all other fragments are assigned the value, $P_{6}=0.055$.

Now the penetration probability tree can be completed. The total probability of a $134^{\circ}$ fan disk section, for example, is $P_{\text {toul }}=P_{1} \times P_{2 a} \times P_{34} \times P_{4} \times P_{5} \times P_{6}$. Various fragment/generic container impact probabilities are listed in Table 3.1.

\subsection{Fragment Penetrating Ability}

A number of factors affect a given engine fragment's ability to penetrate a generic container. As mentioned previously, structures associated with the engine casing, wing, and $f$ selage are neglected in these analyses for conservatism and due to difficulties in quantifying energies absorbed by each structure for various fragments and fragment energies. This assumption was also made in a previous evaluation of the engine fragment threat to containers on aircraft [39].

Along with fragment shape, impact velocity is a critical factor in determining penetrating ability. Neglecting casing, wing, and fuselage structures as potential energy absorbers, impact velocity is identical to rotor burst release velocity. The aircraft engine speed profile for a typical intercontinental flight shown in Figure 2.11 yields an average fragment velocity of $87 \%$ of that associated with a burst at redline speed. An engine experiencing redline speed would be an overspeed event, which is extremely rare, but nonetheless has been known to occur. As mentioned in section 3.2, redline burst speed, and thus impact speed, is conservatively assumed for all penetration analyses and tests. The next chapter on analyses and testing evaluates specific fragment penetrating abilities. 


\section{Penetration Evaluation Methodology}

Evaluation of specific fragment penetrating abilities requires first detailed characterization of the potential fragments, then testing and/or analyses of fragment impacts with the on-board container of interest. Characterization includes gross shape, material parameters, and rotational and translational kinetic energies. Penetration analyses could consist of empirical correlations or detailed dynamic finite element modelling, including advanced capabilities such as hole growth and plugging or fracture. Risk of specific uncontained fragment penetration is the product of fragment/container impact probability and resultant damage severity. Overall risk associated with air transport of a hazardous material within specific containers can be determined by summing the products of individual uncontained fragment impact probabilities and their associr.ted impact consequences, i.e., latent cancer deaths, etc. This Chapter investigates the characterization of four specific example engine fragments, for use in penetration tests or analyses.

A fragment released from a failed rotor has kinetic energy along its line of flight as well as rotational energy about its own center of gravity (c.g.). In passing through an engine casing, a fragment dissipates energy by damaging itself and the casing. Containment tests releasing representative fragments from a rotating arm inside an engine casing showed that a fragment with an energy level just beyond the containment capability of the casing lost $90 \%$ of its translational energy in getting through the casing. But when a portion of rotor, comprising four blades and a piece of disk weighing $6.5 \%$ of the bladed-disk weight, was released inside a casing designed to contain a single blade, the fragment passed through the casing without measurable loss of translational energy. There was, however, a $10 \%$ to $20 \%$ loss of rotational energy and this would account for kinetic energy dissipated in damaging the fragment and the casing [2].

Wilbeck [33] performed a series of tests to further evaluate the effect of disk fragment rotational energy upon penetrating ability. $120^{\circ}$ segments of turbine disks were impacted into steel casings with both rotational and translational velocities of scaled steam turbine fragments. These tests were compared to full-scale $120^{\circ}$ segment impacts into similar steel casings, but with only translational energy (rotational was added as translational). The results showed that the residual energy of the spinning fragments was approximately the same as that of the non-spinning fragments launched in a piercing orientation. Tests with bladed fragments showed that for equal burst speeds, the residual energy of bladed fragments was $10 \%$ less than that of unbladed fragments. The apparent effect of blades was to cushion the local impact and to increase the duration of the impact event, thereby reducing peak stresses and increasing the strain energy absorbed by the target. Also, all or most of the blades were broken off at the root during perforation.

Major conclusions reached by the studies [32,33] were as follows: (1) Since the mitigating effects of blades in absorbing energy and cushioning impact more than compensate for the increase in mass and moment of inertia contributed by the blades, neglecting the blades during impact appears conservative in predicting exit conditions, (2) For penetration tests and analyses of unbladed fragments, it appears valid to assume that a good estimate of the total energy absorbed in ring perforation can be obtained using a non-spinning fragment with a resultant translational 
energy equal to the sum of the initial translational and rotational energies of a spinning fragment, (3) It appears reasonable to neglect the mass of the blades in predicting the residual mass of the fragment that has exited the casing, and (4) a disk fragment with a sharp or piercing orientation will penetrate casings much more readily than one in a blunt orientation.

An analysis of the rotational vs. translational components of kinetic energy in the GE CF6$80 \mathrm{C} 2$ fan blade and 1/3 fan disk yields $94 \%$ and $88 \%$ of the total kinetic energy being translational, respectively. The small proportion of rotational energy suggests that its only effect upon each fragment's penetrating ability is to provide optimal or sub-optimal fragment orientation. For this reason, and due to the conclusions reached by previous experiments, all engine fragments' penetrating abilities will be evaluated with purely translational energy. To avoid excessive conservatism, rotational energies were not added to increase the total translational energy.

Scaled drawings of the stage 1 fan rotor assembly accompanied by key dimensions allows for the determination of all necessary size, shape, and mass properties for a fan blade and 1/3 fan disk, two potentially hazardous uncontained fragments. Data provided by General Electric Co. indicates that individual Ti-6Al-4V fan blades have average dimensions of about $31 \mathrm{in.} \mathrm{long} \mathrm{(from}$ root to tip), 6.4 in. wide, and 0.41 in.thick. The radial distance of a single fan blade's c.g. to the rotor's center of rotation is $31.2 \mathrm{in}$; at a redline velocity of $403.6 \mathrm{rad} / \mathrm{sec}$ (3854 rpm), this yields a translational velocity of $1049 \mathrm{ft} / \mathrm{sec}$. The mass is $14.3 \mathrm{lbm}$ and the translational kinetic energy, defined as $1 / 2 \mathrm{mV}^{2}$, is $2.93 \times 10^{6} \mathrm{lb}$ in. As mentioned previously, the rotational kinetic energy of $0.246 \times 10^{6} \mathrm{lb}$ in., defined as $1 / 2 \mathrm{I} \omega^{2}$ with $\mathrm{I}=1170 \mathrm{lbm}$ in $^{2}$, can be neglected.

Recalling Figure 2.10 , a $134^{\circ}$ disk section (as opposed to a $120^{\circ}, 1 / 3$ disk section) can be assumed for conservatism to maximize translational kinetic energy. Figure 4.1 shows a cross-sectional view of the CF6-80C2 engine with a detailed cross-section of the fan module. The disk and blade material is known to be a titanium-aluminum alloy: Ti-6-4 or Ti-6Al-4V. Assuming a density of $0.161 \mathrm{lbm} / \mathrm{in}^{3}$ the mass of a whole disk is approximately $359 \mathrm{lbm}$ (including rim, web, bore, and arm similar to Figure 2.8).

A solid model (see Figures 4.2 and 4.3) of the fan disk was generated from Figure 4.1, with dimensions approximated in Figure 4.4, to determine projected area and inertial mass properties. The minimum projected area (View A-A in Figure 4.5) for penetration is $77.35 \mathrm{in}^{2}$. The radial distance of the bladed fan disk's c.g. to the rotor's center of rotation is 22.9 in.; at a redline speed of $3854 \mathrm{rpm}$ this yields a translational velocity of $770 \mathrm{ft} / \mathrm{sec}$. The radial distance of a bladeless fan disk's c.g. to the rotor's center of rotation is $10.30 \mathrm{in}$., and its mass moment of inertia is 9824 $\mathrm{lbm} \mathrm{in}^{2}$. The bladeless translational kinetic energy is $1.47 \times 10^{7} \mathrm{lb}$ in. Again, the rotational kinetic energy of $2.07 \times 10^{6} \mathrm{lb}$ in. can be neglected. 
A $45^{\circ}$ fan rim section is another fragment with potential penetrating ability due to its relatively high mass and velocity with low penetrating area. A fully-bladed section, with a centerof-rotation to c.\%. distance of $29.1 \mathrm{in}$. would have a redline release translational velocity of $979 \mathrm{ft} /$ sec. The mass of the bladeless section is $10.76 \mathrm{lbm}$ and its translational kinetic energy would be $3.89 \times 10^{7} \mathrm{ib}$ in. The projected area for penetration of a bladeless $45^{\circ}$ fan rim section is approximately $17.1 \mathrm{in}^{2}$.

Fragments from the high-pressure rotor would also have penetrating potential due to their higher rotation rate $(11,055$ vs. $3,854 \mathrm{rpm})$. Most are much smaller than fan components, though, and all have a smaller ratial distance from center of rotation to fragment c.g., yielding a lower translational velocity upsiı release.

Although high-pressure comyressor blades are more frequently released, high-pressure turbine (HPT) blades should have greater penetrating ability due to their greater mass. HPT blade dimensions are 5.5 in. long by 1.9 in. wide by 0.25 in. thick, as approximated from Figure 2.6. The minimum penetrating area is thus $0.475 \mathrm{in}^{2}$. The radial distance of an HPT blade to the rotor's center of rotation is $18.5 \mathrm{in}$; it a cedline speed of $1158 \mathrm{rad} / \mathrm{sec}(11,058 \mathrm{rpm})$ this yields a translational ve ocity of $1785 \mathrm{ft} / \mathrm{sec}$. Previous CF6-series engines used Inconel 718, with a density of $0.296 \mathrm{lbm} / \mathrm{in}^{3}$ as the HPT blade material. Since no data was available for the CF6-80C2 HPT blade material and inconel 718 is conservatively more dense (yinlding greater penetrating kinetic energy) than Ti-6Al-4V, Inconel 718 can be assumed to be the HPT blade material. A single blade's mass is thus $0.77 \mathrm{lbm}$ and its redline translational kinetic eriergy is $4.57 \times 10^{5} \mathrm{lb}$ in. Similar to the fan blade, the HPT blade's rotational energy can be neglected.

Table 2.1 suggests that fan rims and blades may be more apt to penetrate a given target than a 1/3 fan disk, the so-called worst-case fragment. Validation of this premise requires more detailed penetration analyses and/or tests. Specific dimensions, weights, and velocities can be determined for analyses and tests from numerous sources [40-44].

This characterization data should be useful in the performance of penetration tests and analyses. Multi-layered container designs may be evaluated for penetration resistance by successively analyzing fragment penetrations of individual layers, using the residual kinetic energy from a previous layer as input for the next layer. Other objects, such as wing struts and deflector plate shields may offer further resistance to container penetration by uncontained engine fragments. 


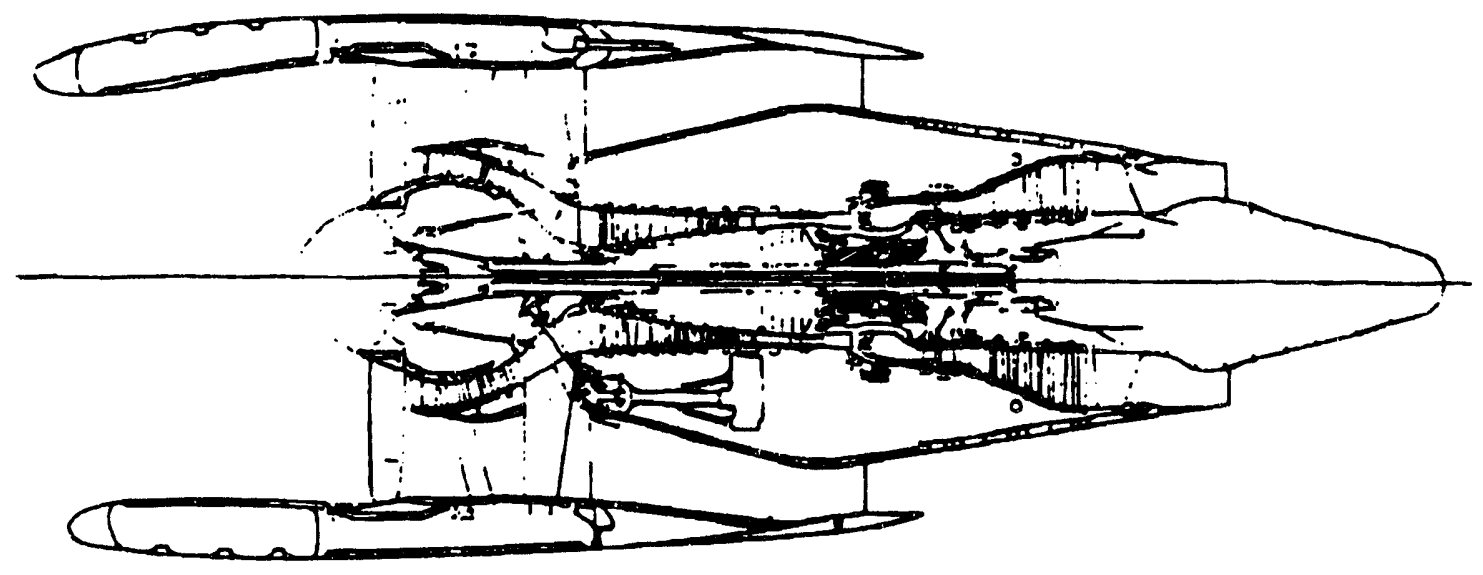

CF6-80C2

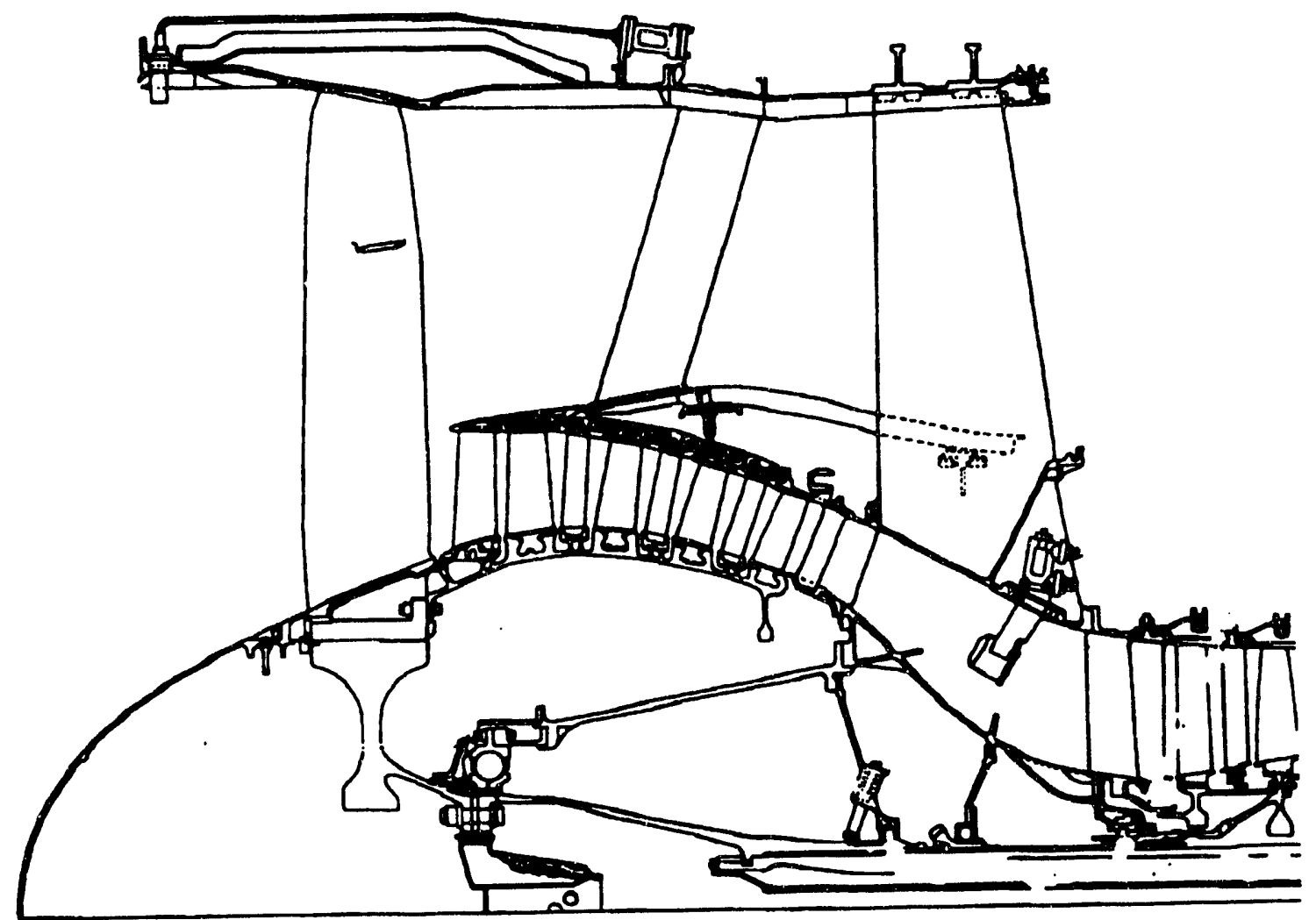

FAN MODULE

Figure 4.1 GE CF6-80C2 engine cross-section with fan module [41] 


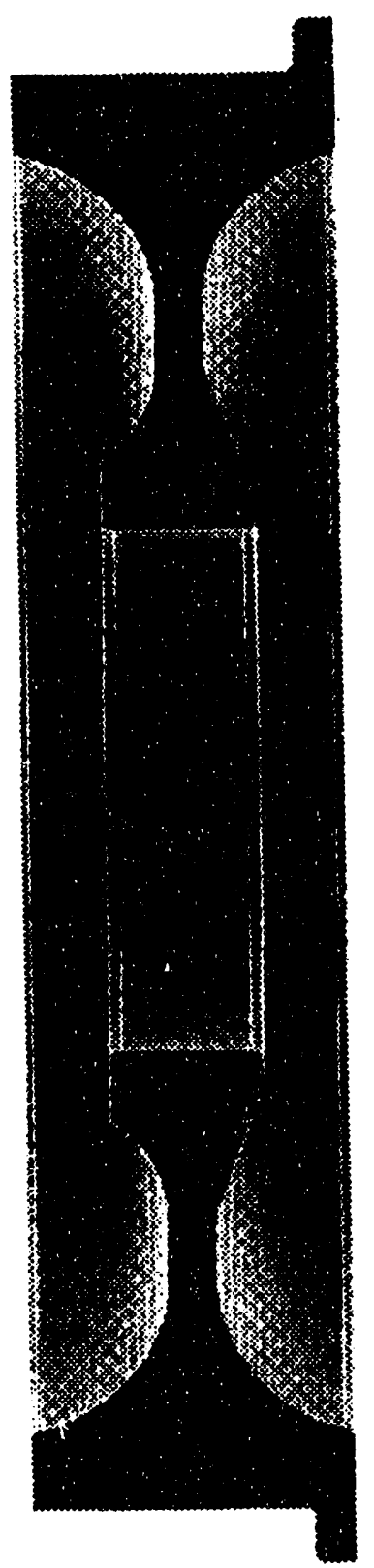

Figure $4.2134^{\circ}$ fan disk segment solid model (bottom view) 


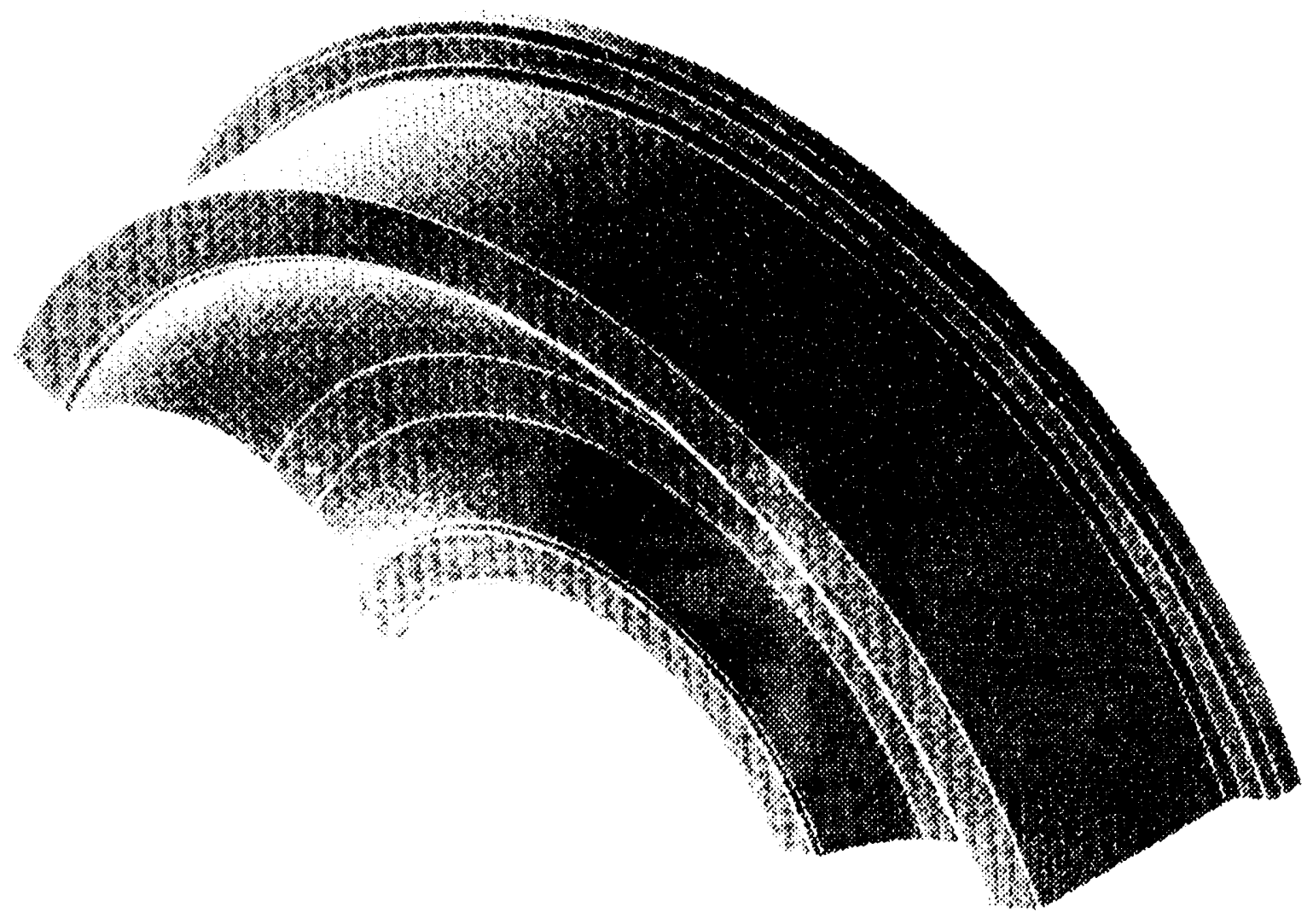

Figure $4.31 .34^{\circ}$ fan disk segment solid model (isometric view) 

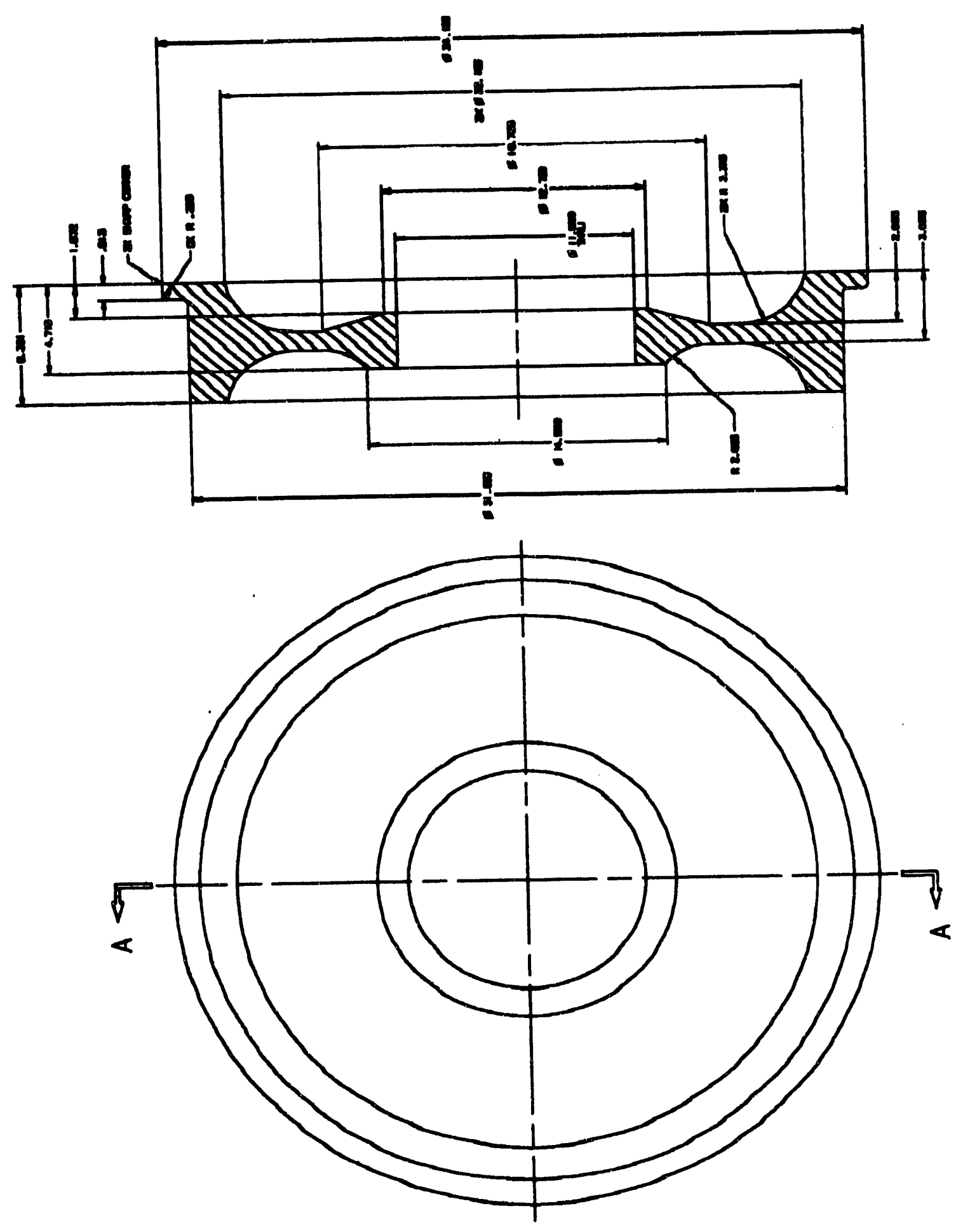

Figure 4.4 Bladeless GE CF6-80C2 fan rotor disk 

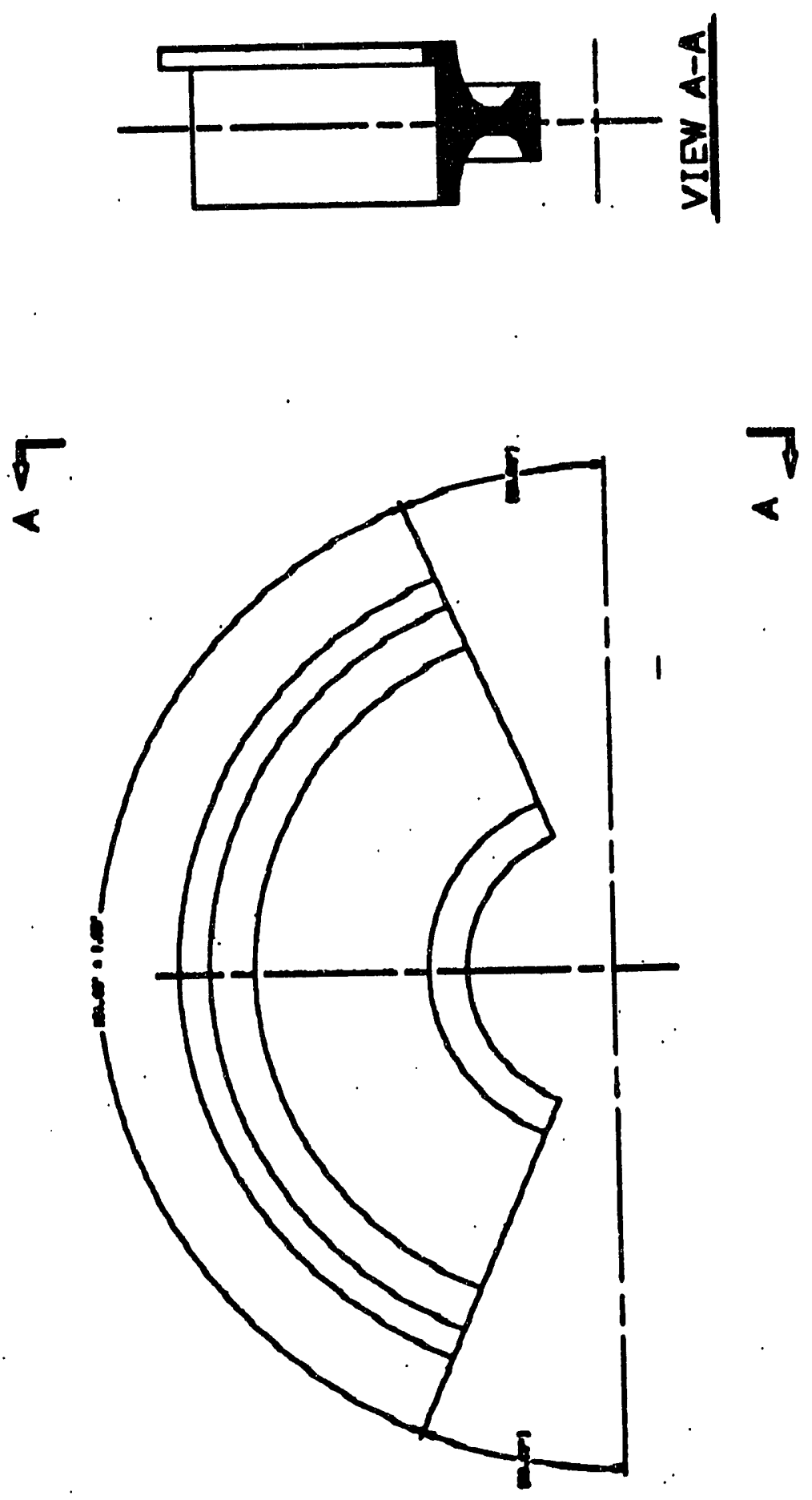

Figure 4.5 Bladeless GE CF6-80C2 fan rotor disk 


\section{Conclusions}

Sandia National Laboratories has developed a methodology to evaluate the hazards to a number of generic on-board containers from uncontained jet engine fragments. A risk assessment approach was taken, so that probability analyses could be combined with quantitative penetration tests or analyses to yield an overall probability of severe containment vessel damage due to uncontained fragments.

A number of conservative assumptions were used in the development of this methodology. A bladeless $134^{\circ}$ fan rotor disk section impacting at redline velocity, for example, may actually experience an approximately $10 \%$ decrease in package impact velocity due to additional blade resistance during engine casing penetration. The assumed redline release velocity may be approximately $15 \%$ higher than actual operational speeds. These two assumptions alone yield a $44 \%$ decrease in disk fragment energy below that of an unobstructed redline release. Additional fragment energy would most likely be expended during penetration of wing and fuselage beams or struts located in the fragment path.

The factor dominating overall fragment impact probability, and thus risk, is uncontained release rate. The FAA rates used in this methodology were compiled in both per-mile and per-hour formats, although the per-hour format was used. These rates are likely conservative when applied to the example probability analysis since they were derived from generally much shorter flight lengths than an intercontinental one, which could take approximately 14 hours. Over 60 percent of uncontained releases occur during taxi, takeoff, and landing, that combine for only a small fraction of the 14-hour flight. Since the release rate data are derived from flights whose mission profiles have more significant duration fractions of taxi, takeoff, and landing, release rate probabilities may be smaller for intercontinental flight profiles with cruise being far more dominant.

The relatively small containment vessel impact probability is reducible to virtually zero simply by omitting as many generic containers that would be located in the potential paths of hazardous engine fragments as necessary from every flight. This decrease in payload per flight negates the package-specific hazards of uncontained jet engine fragments. If decreased payload is unacceptable, the use of relatively small, high-strength deflector plates could be investigated to help protect the generic containers. Detailed dynamic finite element analyses and/or fragment impact tests are necessary to evaluate package-specific uncontained fragment penetration abilities. 


\section{References}

[1] Stotler, C. L., and Coppa, A. P., "Containment of Composite Fan Blades," NASA-CR159544, General Electric Company, July 1979.

[2] Witmer, E. A., "An Assessment of Technology for Turbojet Engine Rotor Failures," NASA CP-2017, Massachusetts Institute of Technology, Cambridge, MA, 1977.

[3] McCarthy, D., "Definition of Engine Debris and Some Proposals for Reducing Potential Damage to Aircraft Structure," Specialists Meeting on Impact Damage Tolerance of Structures, Paris, France, January 1976.

[4] Coombe, T. W., "Structural Effects of Engine Burst Non Containment," Specialists Meeting on Impact Damage Tolerance of Structures, Paris, France, January 1976.

[5] Witmer, E. A., Stagliano, T. R., and Rodal, J. J. A., "Engine Rotor Burst Containment/Control Studies," AGARD Conference Proceedings No. 248, Massachusetts Institute of Technology, Cambridge, MA, October 1978.

[6] NTSB, "Special Study - Turbine Engine Rotor Disk Failures," NTSB-AAS-74-4, December 18, 1974.

[7] Delucia, R. A., and Salvino, J. T., "Statistics on Aircraft Gas Turbine Engine Rotor Failures that Occurred in U.S. Commercial Aviation During 1986," DOT/FAA/CT-89/30, Naval Air Propulsion Center, Trenton, NJ, January 1990.

[8] Delucia, R. A., and Salvino, J. T., "Statistics on Aircraft Gas Turbine Engine Rotor Failures that Occurred in U.S. Commercial Aviation During 1985," DOT/FAA/CT-89/7, Naval Air Propulsion Center, Trenton, NJ, July 1989.

[9] DeLucia, R. A., and Salvino, J. T., "Statistics on Aircraft Gas Turbine Engine Rotor Failures that Occurred in U.S. Commercial Aviation During 1984," DOT/FAA/CT-89/6, Naval Air Propulsion Center, Trenton, NJ, June 1989.

[10] Delucia, R. A., and Salvino, J. T., "Statistics on Aircraft Gas Turbine Engine Rotor Failures that Occurred in U.S. Commercial Aviation During 1983," DOT/FAA/CT-89/5, Naval Air Propulsion Center, Trenton, NJ, March 1989.

[11] Delucia, R. A., and Salvino, J. T., "Statistics on Aircraft Gas Turbine Engine Rotor Failures that Occurred in U.S. Commercial Aviation During 1982," DOT/FAA/CT-88/23, Naval Air Propulsion Center, Trenton, NJ, July 1988.

[12] Delucia, R. A., Salvino, J. T., and Russo, T.,"Statistics on Aircraft Gas Turbine Engine Rotor Failures that Occurred in U.S. Commercial Aviatio. 1 During 1981," DOT/FAA/CT-86/42, Naval Air Propulsion Center, Trenton, NJ, March 1987. 
[13] DeLucia, R. A., Salvino, J. T., and Gagliardi, L. J.,"Statistics on Aircraft Gas Turbine Engine Rotor Failures that Occurred in U.S. Commercial Aviation During 1980," NASA CR-174830, Naval Air Propulsion Center, Trenton, NJ, September 1984.

[14] Delucia, R. A., and Salvino, J. T.,"Statistics on Aircraft Gas Turbine Engine Rotor Failures that Occurred in U.S. Commercial Aviation During 1979," NASA CR-168163, Naval Air Propulsion Center, Trenton, NJ, October 1982.

[15] Delucia, R. A., and Salvino, J. T.,"Statistics on Aircraft Gas Turbine Engine Rotor Failures that Occurred in U.S. Commercial Aviation During 1978," NAPC-PE-23, Naval Air Propulsion Center, Trenton, NJ, September 1981.

[16] Delucia, R. A., and Salvino, J. T.,"Statistics on Aircraft Gas Turbine Engine Rotor Failures that Occurred in U.S. Commercial Aviation During 1977," NASA CR-165388, Naval Air Propulsion Center, Trenton, NJ, July 1979.

[17] DeLucia, R. A., and Salvino, J. T., "Rotor Fragment Protection Program: Statistics on Aircraft Gas Turbine Engine Rotor Failures that Occurred in U.S. Commercial Aviation During 1976," NASA-CR-159474, Naval Air Propulsion Center, Trenton, NJ, July 1978.

[18] DeLucia, R. A., and Mangano, G. J.,"Statistics on Aircraft Gas Turbine Engine Rotor Failures that Occurred in U.S. Commercial Aviation During 1975," NASA CR-135304, Naval Air Propulsion Center, Trenton, NJ, May 1977.

[19] DeLucia, R. A., and Mangano, G. J.,"Statistics on Aircraft Gas Turbine Engine Rotor Failures that Occurred in U.S. Commercial Aviation During 1974," NASA CR-134855, Naval Air Propulsion Center, Trenton, NJ, September 1975.

[20] Mangano, G. J., and DeLucia, R. A., "Rotor Burst Protection Program: Statistics on Aircraft Gas Turbine Engine Rotor Failures that Occurred in U.S. Commercial Aviation During 1973," ASME publication 75-GT-12, Naval Air Propulsion Test Center, Trenton NJ, March 1975.

[21] FAA Advisory Circular, "Design Considerations for Minimizing Hazards Caused by Uncontained Turbine Engine and Auxiliary Power Unit Rotor and Fan Blade Failures," March 1988.

[22] Civil Aviation Authority, Airworthiness Information Leaflet, "Non-containment of Turbine Engine Debris," AD/IL/0042/1-7, June 1976.

[23] McCarthy, D., "Types of Rotor Failure and Characteristics of Fragments," NASA CP-2017, Rolls-Royce Limited, Derby, UK, March 1977.

[24] SAE, “Report on Aircraft Engine Containment," AIR 4003, September 1987.

[25] Gunstone, G. L., "Engine Non-Containment-The UK CAA View," UK Civil Aviation Authority, N78-10070. 
[26] SAE Aerospace Information Report, "Report on Aircraft Engine Containment," AIR 1537, October 1977.

[27] NTSB, “Aircraft Accident Report, United Airlines Flight 232, Sioux City, Iowa, July 19, 1989," PB90-910406, NTSB/AAR-90/06.

[28] Code of Federal Regulations, Volume 14, Part 33 Airworthiness Standards: Aircraft Engines, Section 19, January 1, 1988.

[29] Mangano, G. J., "Studies of Engine Rotor Fragment Impact On Protective Structure," Specialists Meeting on Impact Damage Tolerance of Structures, Paris, France, January 1976.

[30] Warwick, G., and Marsden, J., “GE's Big Fan Gets Bigger,” Flight International, pp. 27-34, May 23, 1987.

[31] Treager, I. E., "Aircraft Gas Turbine Engine Technology," 2nd Edition, McGraw-Hill, 1979.

[32] Yoshimura, H. R., and Schamaun, J. T., "Full-Scale Turbine Missile Casing Tests," EPRI NP-2741, Project 399-1, January, 1983.

[33] Wilbeck, J. S., "Tests of Spinning Turbine Fragment Impact on Casing Models," Nuclear Engineering and Design, 77, 1984.

[34] Backman, M. E., and Goldsmith, W., "The Mechanics of Penetration of Projectiles into Targets," Int. J. Engr. Sci, Vol. 16, pp. 1-99, 1978.

[35] Mileiko, S. T., Kondakov, S. F., and Golofast E. G., "One Case of Piercing," Institute of Solid-State Physics, Translated from Problemy Prochnosti, No. 12, pp. 69-71, December 1979.

[36] Awerbuch, J. and Bodner, S. R., "An Investigation of Oblique Perforation of Metallic Plates by Projectiles," Experimental Mecharics, pp. 147-153, April 1977.

[37 Zukas, J. A., Editor, "High Velocity Impact Dynamics," John Wiley and Sons, Inc., New York, 1990.

[38] Office of Nuclear Material Safety and Safeguards, U.S. Nuclear Regulatory Commission, "Qualification Criteria to Certify a Package for Air Transport of Plutonium," NUREG-0360, Washington, DC, January 1978.

[39] Hartman, W. F., Von Reisemann, W. A., and McClure, J. D.,"An Analysis of the Engine Fragment Threat and the Crush Environment for Small Containers Carried on U.S. Commercial Jet Aircraft," Proceedings of the Fifth Int'l Symposium on Packaging and Transportation of Radioactive Materials, Las Vegas, Nevada, May, 1978. 
[40] Donoghue, J. A., "CF6-80C2 Logs Hours as Competitors Enter Starting Gate," Air Transport World, Vol 24(3), 1987.

[41] Written correspondence from S. J. Zigan (Manager, Aircraft Programs, GE Aircraft Engines) to J. L. Moya, Sandia National Laboratories, September 12, 1989.

[42] “Boeing 747-400 Flight Test," Flight International, November 12, 1988.

[43] Jane's All The World's Aircraft, 1990-91.

[44] Department of Transportation, Federal Aviation Administration, Specification Sheet for GE CF6-80 Series Engines.

[45] Personal communication with R. Snow, The Boeing Co., June 7, 1991. 


\section{Distribution List}

No. of

Copies

1 U. S. Department of Energy

Office of Environmental

Restoration and Waste

Management

Attn: Paul Grimm, Actg.

Director, EM-1

Mail Stop EM-1

7A-049

1000 Independence SW

Washington, DC 20585

1 U. S. Department of Energy

Office of Technology

Development

Attn: Clyde Frank, Associate

Director, EM-50

7A-049

1000 Independence SW

Washington, DC 20585

1 U. S. Department of Energy

Office of Waste Operations

Attn: S. P. Cowen, EM-30

Mail Stop EM-30

A-214A

19901 Germantown Foad

Germantown, MD 20585

2 U. S. Department of Energy

Office of Waste Operations

Attn: J. Lytle, EM-30

L. Harmon, EM-30

Mail Stop EM-30

1 U. S. Department of Energy

Albuquerque Operations Office

Albuquerque Headquarters

Attn: J. Bickel

P. A. Saxman

K. G. Golliher

P. O. Box 5400

D. Bandy

Albuquerque, NM 87115

5 U. S. Department of Energy

Attn: R. Brancato, EM-56

L Blalock, EM-561

M. Conroy, EM-561

M. Keane, EM-561

E. McNeil, EM-561

Mail Stop EM 56

Washington, D.C. 20545

2 U. S. Department of Energy

Office of Civilian Waste Management

Attn: W. Lake, RW-431

Mail Stop RW-40

1000 Independence SW

Washington, DC 20585

1 U. S. Department of Energy Oak Ridge Operations Office

Attn.: M. Heiskell

P. O. Box E

Oak Ridge, TN 37831

7A-049

1000 Independence SW

Washington, DC 20585 
1 U. S. Department of Energy Oak Ridge Operations Office

Att.: M. Heiskell

P. O. Box E

Oak Ridge, TN 37831

1 Argonne National Laboratory

Attn: G. Popper

9700 South Cass Ave.

Argonne, IL 60439

1 U. S. Department of Transportation Office of Materials Transportation Attn: K. Smith 400 Seventh Street, SW Washington, DC 20590

2 U.S. Nuclear Regulatory Commission Office of Nuclear Materials Safety and Safeguards

Attn: R. Chappell

C. MacDonald

Washington, DC 20555

1 Frank Falci

8905 Copenhaver Drive

Potomac, MD 20854

1 Eric Opperman

Packaging and Transportation Group Westinghouse Savannah River Co. Savannah River Laboratories

P. O. Box A

Aiken, SC 29802

1 Joanne Passaglia

Transportation Management Program Office of Technology Development

U. S. Department of Energy

Trevion II Building, EM-561

Washington, DC 20585
1 Bill Pearson

U. S. Department of Energy

704 S Area

Field Office, Savannah River

P.O. Box A

Aiken, SC 29808

1 Ronald Pope

Oak Ridge National Laboratory

P. O. Box 2008

Building 4500N, MS-273

Oak Ridge, TN 37831-6273

1 Frank Punch

Packaging and Transportation Specialist

EH-33.3 GTN

U. S. Department of Energy

Washington, DC 20585-0001

1 James Szenasi

OPEP

U. S. Department of Energy

Field Office, Albuquerque

P. O. Box 5400

Albuquerque, NM 87115

1 Bob Towell

U. S. Department of Energy

19901 Germantown Road, EH-33.3

Germantown, MD 20874

1 Mike Wangler

Transportation and Packaging

Safety Division

U. S. Department of Energy, EH-33.3

Room 6138

19901 Germantown Road

Germantown, MD 20874 
Internal Distribution:

No. of

Copies

$\begin{array}{rll}1 & 123 & \text { J. C. Garrison } \\ 1 & 0324 & \text { P. E. D'Antonio } \\ 1 & 0333 & \text { C. G. Shirley } \\ 1 & 5165 & \text { N. R. Hansen } \\ 1 & 5365 & \text { G. C. Story } \\ 1 & 5365 & \text { R. D. Monson } \\ 1 & 6000 & \text { D. L. Hartley } \\ 1 & 6600 & \text { J. B. Woodard } \\ 1 & 6603 & \text { R. E. Luna } \\ & & \text { Attn. TTC Master File } \\ 30 & 6603 & \text { TTC Library } \\ 1 & 6603 & \text { R. M. Baehr } \\ 1 & 6641 & \text { R. P. Sandoval } \\ 1 & 6641 & \text { J. D. McClure } \\ 1 & 6642 & \text { G. F. Hohnstreiter } \\ 1 & 6642 & \text { D. J. Ammerman } \\ 1 & 6643 & \text { T. L. Sanders } \\ 15 & 6642 & \text { D. C. Harding } \\ 15 & 6642 & \text { J. D. Pierce } \\ 1 & 6642 & \text { K. B. Sorenson } \\ 5 & 7141 & \text { Technical Library } \\ 1 & 7151 & \text { Technical Publications } \\ 10 & 7613-2 & \text { Document Processing for DOE/OSTI } \\ 1 & 8523-2 & \text { Central Technical Files }\end{array}$



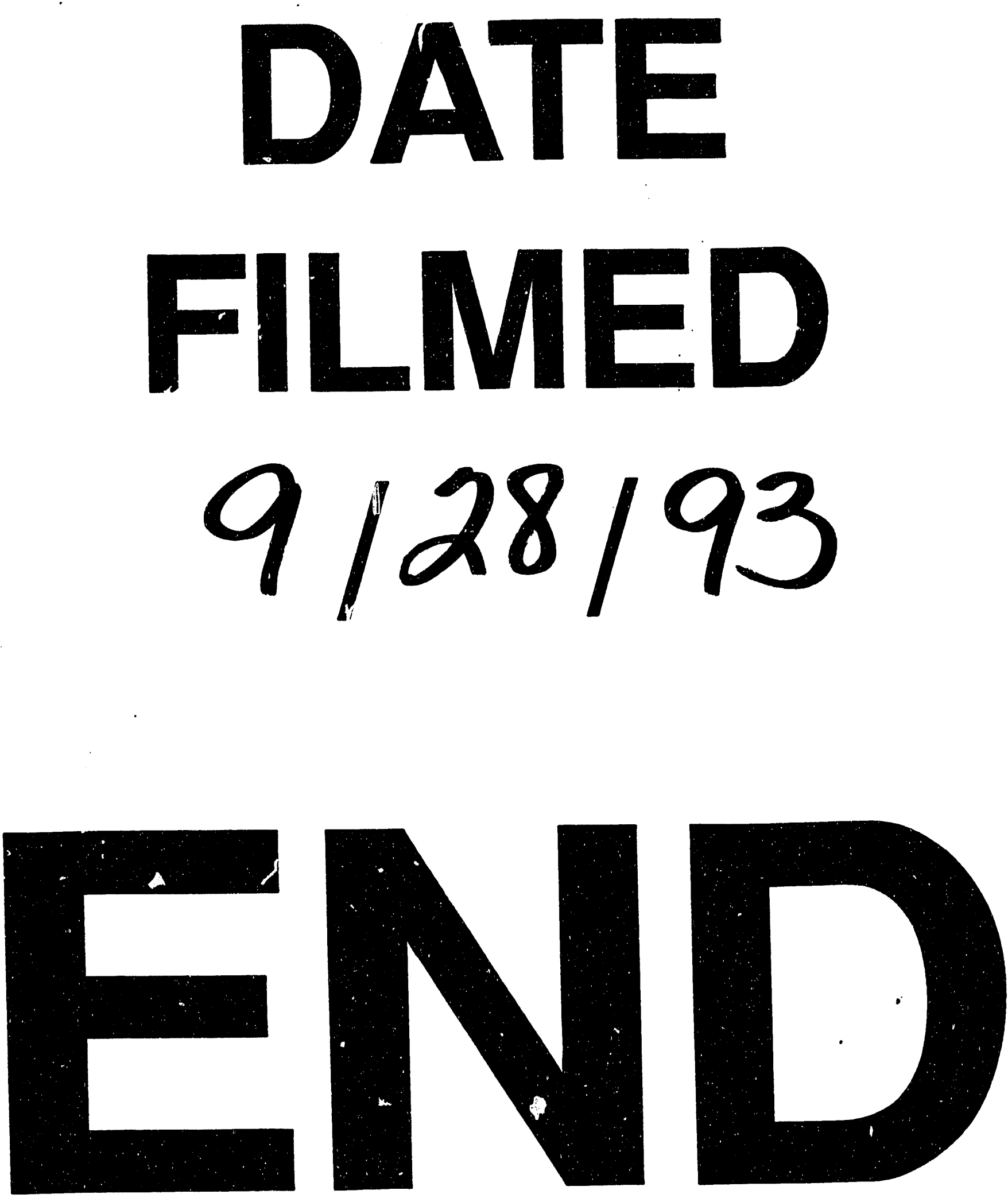
